\title{
Development of a Novel Staging Model for Affective Disorders Using Partial Least Squares Bootstrapping: Effects of Lipid-Associated Antioxidant Defenses and Neuro-Oxidative Stress
}

Michael Maes a,b,c,d, Juliana Brum Moraes a , Ana Congio a , Kamila Landucci Bonifacio a, Decio Sabbatini Barbosa a , Heber Odebrecht Vargas a , Ana Paula Michelin a, Andre F. Carvalho e,f, Sandra Odebrecht Vargas Nunes ${ }^{\text {a }}$

${ }^{a}$ Health Sciences Graduate Program, Health Sciences Center, State University of Londrina, Av. Robert Koch 60 ; 86035-380, Londrina, PR, Brazil;

${ }^{\mathrm{b}}$ Department of Psychiatry, Chulalongkorn University, Bangkok, Thailand;

${ }^{c}$ Department of Psychiatry, Medical University of Plovdiv, Plovdiv, Bulgaria;

d IMPACT Strategic Research Centre, Deakin University, Geelong, Vic, Australia;

${ }^{\mathrm{e}}$ Department of Psychiatry, University of Toronto, Toronto, ON, Canada;

${ }^{\mathrm{f}}$ Centre for Addiction and Mental Health (CAMH), Toronto, ON, Canada.

Corresponding author:

Prof. Dr. M. Maes, M.D., Ph.D.

IMPACT Strategic Research Centre,

School of Medicine

Deakin University,

PO Box 281

Geelong 3220

Australia

dr.michaelmaes@hotmail.com

http://scholar.google.co.th/citations?user=1wzMZ7UAAAAJ\&hl=th\&oi=ao\&cstart=100\&pagesi $\underline{\mathrm{ze}=100}$

dr.michaelmaes@hotmail.com

julianabrumpsiq@gmail.com

anacongio@portalcinp.com.br

kamilalondrina@hotmail.com

sabbatini2011@hotmail.com

hebervargas@sercomtel.com.br

paulimichelin10@gmail.com

andrefc7@hotmail.com

sandranunes@sercomtel.com.br 


\begin{abstract}
Although, staging models gained momentum to stage define affective disorders, no attempts were made to construct mathematical staging models using clinical and biomarker data in patients with major depression and bipolar disorder.

The aims of this study were to use clinical and biomarker data to construct statistically-derived staging models, which are associated with early lifetime traumata (ELTs), affective phenomenology and biomarkers.

In the current study, 172 subjects participated, 105 with affective disorders (both bipolar and unipolar) and 67 controls. Staging scores were computed by extracting latent vectors (LVs) from clinical data including ELTs, recurring flare ups and suicidal behaviors, outcome data such as disabilities and health-related quality of life (HR-QoL), and paraoxonase (PON)1 actvities and nitro-oxidative stress biomarkers.

Recurrence of episodes and suicidal behaviors could reliably be combined into a LV with adequate composite reliability (the "recurrence LV"), which was associated with female sex, the combined effects of multiple ELTs, disabilities, HR-QoL and impairments in cognitive tests. All those factors could be combined into a reliable "ELT-staging LV" which was significantly associated with nitrooxidative stress biomarkers. A reliable LV could be extracted from serum PON1 activities, recurrent flare ups, disabilities and HR-QoL.

Our ELT-staging index scores the severity of a relevant affective dimension, shared by both major depression and bipolar disorder, namely the trajectory from ELTs, a relapsing course and suicidal behaviors to progressive disabilities. Patients were classified into three stages, namely an early stage; a relapse-regression stage; and a suicidal-regression stage. Lowered lipid-associated antioxidant defenses may be a drug target to prevent the transition from the early to the later regression stages.
\end{abstract}

Keywords: staging, affective disorders, major depression, bipolar disorder, oxidative, neuroimmune

\title{
Introduction
}

The trajectory of affective disorders is characterized by specific lifetime epochs, including childhood lifetime traumata (ELTs), recurrent depressive and manic episodes, suicidal behaviors alternating with euthymic phases, and a residual stage with neurocognitive deficits, functional impairments and brain alterations [1-4]. Both major depression (MDD) and bipolar disorder (BD) are progressive disorders whereby the number of episodes is associated with increased symptomatic severity, functional decline in daily task performance, higher risk of future episodes and increased risk for impairments in neurocognitive functions, including memory and executive functions [3,5,6,7]. Nevertheless, the current nosological classifications of affective disorders are mainly based on symptoms and polarity course characteristics of the disorder and do not consider the preceding risk factors, including ELTs, severity of the recurring pattern of the disease, suicidal behaviors and deteriorated outcome characteristics, including disabilities, lowered health-related quality of life (HR-QoL) and neurocognitive deficits, which are all associated with the course of the illness [7].

As such, affective disorders are not stage-defined, although diagnostic criteria based on staging may provide more appropriate and targeted treatments to prevent further episodes and progression into the later stages, which are characterized by functional and cognitive decline [8]. Recently, some authors proposed staging models by dividing bipolar disorder or major depression 
into relevant stages based on risk factors, such as family history of mental illness, prodromal patterns, relapses of episodes, refractory states, and interepisodic functioning including cognitive impairments, comorbidities and functional impairments [9-11]. Nevertheless, these staging models were not based on predictive mathematical algorithms derived from biomarkers and clinical data including ELT, recurrent episodes and suicidal behaviors, neurocognitive deficits and functional impairments.

There is now evidence that depressive and (hypo)manic episodes have detrimental effects on neuronal functions in the brain as exemplified by changes in neurocognitive functions, overall psychological disabilities and brain imaging techniques [3]. There is also evidence that major depression and bipolar disorder are neuro-immune and neuro-oxidative disorders with increased levels of pro-inflammatory cytokines and acute phase proteins, such as haptoglobin and C-reactive protein (CRP) $[12,13]$. These disorders are also characterized by lowered lipid-associated antioxidant defenses, in particular lower high-density lipoprotein cholesterol and paraoxonase 1 (PON1), by increased lipid peroxidation, as indicated by increased lipid hydroperoxides (LOOH) and aldehyde formation (e.g., malondialdehyde, MDA), by increased production of nitric oxide and hypernitrosylation, and by increased protein oxidation as indicated by increased levels of advanced protein oxidation products (AOPPs) [12-16]. The working hypotheses are that a) activated neuro-immune and neuro-oxidative pathways cause detrimental effects on brain circuitry through the effects of pro-inflammatory cytokines, reactive oxygen and nitrogen species (ROS/RNS) and hypernitrosylation; and b) lowered lipid-associated antioxidant defenses, including lowered levels of HDL-cholesterol, coenzyme Q10, omega-3 polyunsaturated fatty acids and vitamin E, lowered activities of lecithin cholesterol acyltransferase (LCAT) and PON1, reduce neuroprotection and increased vulnerability to develop nitro-oxidative stress [17-29]. These adverse effects comprise cytotoxic, excitotoxic and neurotoxic effects that cause dysfunctions in neurogenesis, apoptotic mechanisms, receptor expression, neuroplasticity and neuronal functions $[3,15,16]$. Interestingly, there is some evidence that increased numbers of relapses are accompanied by activated neuro-immune and neuro-oxidative pathways, as indicated by increased levels of neopterin, pro-inflammatory cytokines and malondialdehyde [30,31]. Most importantly, we showed that the number of depressive and (hypo)manic episodes could be combined with lowered PON1 activity and HDL-cholesterol levels into a reliable underlying construct (latent vector), which further mediated the effects of ELTs on oxidative stress biomarkers and affective phenomenology, including lowered health-related quality of life (HR-QoL), increased disabilities, neurocognitive deficits, current suicidal ideation, socioeconomic status, use of medication and severity of illness [7]. Nevertheless, this study examined the staging effects of recurrent patterns of depressive and (hypo)manic episodes and PON1/HDL-cholesterol, but not a comprehensive staging index, including ELTs, recurrent patterns of episodes and suicidal behaviors, increased disabilities, lowered HR-QoL, neurocognitive deficits and oxidative and inflammatory biomarkers. Finally, there is also some evidence that staging characteristics of both affective disorders may be accompanied by metabolic disorders including increased body mass index (BMI), the metabolic syndrome (MetS), changes in thyroid secreting hormone (TSH) and increased insulin resistance $[32,33]$.

Hence, the aim of the present study was to construct a predictive staging index/model based on ELTs, recurrent patterns of episodes and suicidal behaviors, increased disabilities, lowered HRQoL, neurocognitive deficits and immune, oxidative and metabolic biomarkers. 


\section{Subjects and Methods}

\section{Participants}

In this study, 172 participants were recruited, including 105 patients with affective disorder, 68 patients diagnosed with BD and 37 patients with MDD, and 67 healthy controls. All patients with affective disorders were in partial remission or remission, while the index episode was not of (hypo)manic polarity. All participants were of Brazilian nationality, were of both genders and were aged 20 to 63 years. We included all self-declared ethnicities. All patients were outpatients admitted to the University Hospital of the State University of Londrina (UEL), Parana, Brazil. Controls were recruited by word of mouth from the same catchment area. In addition, 81 of the participants showed anxiety disorders according to DSM-5 criteria, namely, social phobia, simple phobia, generalized anxiety disorder (GAD) or panic disorder. Diagnoses of MDD, BD (types 1 and 2), the 4 anxiety disorders and tobacco use disorder (TUD) were made using the diagnostic criteria of the Diagnostic and Statistical Manual of Mental Disorders, 4th Edition, Text Revision (DSM-IV-TR).

Exclusion criteria were: a) any other axis-1 DSM-IV-TR disorder, including schizophrenia, schizo-affective disorder, autism, psycho-organic syndromes and substance abuse disorders; b) participants with neurodegenerative / neuroinflammatory disorders such as Parkinson's disease, Alzheimer's disease, and multiple sclerosis; c) (auto)immune disorders including inflammatory bowel disease, psoriasis, cancer, chronic kidney disease, rheumatoid arthritis, type 1 diabetes, chronic obstructive pulmonary disease, systemic lupus erythematosus, HIV and hepatitis B/C virus infection; d) treatments with immune-regulatory drugs, nonsteroidal anti-inflammatory drugs, glucocorticoids, interferon, and antioxidant and omega-3 polyunsaturated fatty acid supplements; and e) pregnant women. All participants provided written informed consent to take part in the study, whose experimental procedures were previously approved by the Research Ethics Committee at UEL (protocol number: CAAE 34935814.2.0000.5231).

\section{Methods}

A research psychiatrist made the clinical assessment of axis I diagnoses employing a validated Portuguese version of the structured clinical interview for DSM-IV interview (SCID) axis I [34,35] and the DSM-IV-TR diagnostic criteria. The research psychiatrist used a structured interview to assess sociodemographic (marital status, education, income, employment status, and ethnicity) and clinical (number of previous depressive, hypomanic and manic episodes) data. Marital status was registered as married + live together versus widowed + single, education was registered as number of education years, employment status was registered as working versus not working + pension + disability payment, and income was computed on a US dollar/month scale and classified as follows: $0=$ up to US\$ $300,1=\$ 300$ to $\$ 600 ; 2=\$ 600$ to $\$ 1000 ; 3=\$ 1000$ to $\$ 1500$; and $4=$ over $\$ 1500$ a month). Treatment with psychotropic medications was registered showing that some participants were treated with antidepressants $(n=44)$, lithium $(n=26)$, atypical antipsychotics $(n=32)$ and anticonvulsant mood stabilizers $(n=33)$. Previously, we showed that using the same study sample there were no significant effects of these psychotropic drugs on the biomarkers used here [12].

We used the Hamilton Depression (HAM-D) and Anxiety (HAM-A) Rating Scales to assess severity of depression and anxiety, respectively [36,37] and we used the Young Mania Rating Scale (YMRS) to assess severity of hypomanic symptoms [38]. Disabilities were assessed 
using the Sheehan scale [39]., which is a self-administered rating scale with scores of 0-10 in domains including occupational, social life, leisure, family life, activities and household activities, whereby a score of 0-3 indicates mild disabilities, 4-6 indicates moderate disabilities and 7-10 indicates severe disabilities. HR-QoL was assessed using the WHO Quality of Life InstrumentAbbreviated Version (WHOQOL-BREF) in a validated Brazilian Portuguese translation [40-42]. This instrument comprises 26 items and measures 4 HR-QoL subdomains, namely, physical health, psychological health, social relationships and environment. In the current study, we employed the sum of the raw scores on these 26 items as an overall index of HR-QoL. We used the Clinical Global Impressions (CGI) scale to measure overall severity of illness, which scores the subject status on a scale from 1 to 7 [43]. The Columbia-Suicide Severity Rating Scale (C-SSRS) was employed in a validated Portuguese translation to measure current suicidal ideation, number of prior suicide attempts and life-time suicidal ideation [44]. A subset of the participants $(n=84)$ also completed the Verbal Fluency Test (VFT), animal category, and the trail-making test, part A, which probes cognitive processing speed (TMT_A), and part B, which probes executive functioning (TMT_B) [45,46].

The Childhood Trauma Questionnaire (CTQ) is a self-rated scale for adults and adolescents that measures severity of ELT with scores on a five point Likert scale reflecting the frequency of reported events in childhood. The CTQ comprises 28 items divided into 5 domains, including sexual abuse, physical abuse, emotional abuse, emotional neglect and physical neglect [47]. In our study, we used the validated Brazilian Portuguese version [48]. Body mass index (BMI) was computed according to weight (in $\mathrm{kg}$ ) divided by square of height (in $\mathrm{m}^{2}$ ). The diagnosis of metabolic syndrome (MetS) was made employing the criteria of the International Diabetes Federation; i.e., 3 criteria of the following should be present: (a) abdominal obesity (waist circumference $\geq 90 \mathrm{~cm}$ for men and $\geq 80 \mathrm{~cm}$ for women in South Asian and South Americans and $\geq 94.0 \mathrm{~cm}$ for men and $\geq 80.0 \mathrm{~cm}$ for women in Caucasians); (b) low HDL-cholesterol ( $<40 \mathrm{mg} / \mathrm{dL}$ in men and $<50 \mathrm{mg} / \mathrm{dL}$ in women) or use of hypolipidemic drugs; (c) hypertriglyceridemia (triglycerides $>150 \mathrm{mg} / \mathrm{dL}$ ) or use of a hypolipidemic agent; (d) increased fasting glucose ( $>100$ $\mathrm{mg} / \mathrm{dL}$ ) or use of oral antidiabetic medications; and (e) increased average blood pressure (130/85 $\mathrm{mm} \mathrm{Hg}$ ) or currently taking antihypertensive medication.

Assays

Blood was sampled after an overnight fast at 8 a.m. on the same day that we completed the structured interview, including severity rating scales and clinical diagnoses. We measured the activities or levels of superoxide dismutase (SOD), uric acid, LOOH, NO metabolites (NOx), MDA, AOPP, HDL-cholesterol, PON1, thyroid secreting hormone, hsCRP, insulin and glucose. The HOMA2-insulin resistance index (the HOMA2IR index was calculated according to Levy et al. [49]. The assays of the first eight biomarkers were described previously [12]. Briefly, SOD1 activity in erythrocytes was determined using the pyrogallol method described by Marklund and Marklund [50]. This technique is based on the inhibition of pyrogallol self-oxidation by SOD in aqueous solution. The assay was conducted in a spectrophotometer Helios $\forall$ (Thermo Spectronic, Waltham, MA, USA) at $420 \mathrm{~nm}$ and $37^{\circ} \mathbf{C}$. Variation in optical density (OD) was recorded every minute for 5 minutes. The level of SOD that inhibited $50 \%$ of the pyrogallol oxidation was defined as one unit of enzymatic activity. The results were expressed in U/mg of hemoglobin $(\mathrm{Hb})$. $\mathrm{LOOH}$ was assayed by chemiluminescence (CL-LOOH) [51,52]. This method uses the compound tertbutyl hydroperoxide to initiate a lipid chain reaction that can be detected by photon emission 
during the formation of lipid hydroperoxides. Readings were performed in a Glomax luminometer (TD 20/20 Turner Designers, USA) over $1 \mathrm{~h}$ at 1 reading per second. The results are expressed as relative units of light (RLU). NOx levels were assessed indirectly by determining the plasma nitrite concentration using an adaptation of the technique described by Navarro-Gonzalvez et al. [53]. This method is based on the reduction of the nitrate present in the sample to nitrite by oxidationreduction reactions mediated by the system cadmium-copper reagent. Then, Griess reagent was added to induce diazotization, forming a colored complex and subsequent detection at $540 \mathrm{~nm}$. The quantification of NOx was made in a microplate reader Asys Expert Plus, Biochrom (Holliston, MA, USA). AOPP was quantified using the method described by Hanasand et al. [54] in a microplate reader, Perkin Elmer, model EnSpire (Waltham, MA, USA) at a wavelength of 340 $\mathrm{nm}$. AOPP concentration was expressed in :M of equivalent chloramine T. Based on these 4 nitrooxidative measurements we have computed a $\mathrm{z}$ unit weighted composite score reflecting the path from superoxide production to AOPP production, namely, zSOD+LOOH+NOx+AOPP [12]. This index was computed as $\mathrm{z}$ transformation of SOD (zSOD) $+\mathrm{z} \mathrm{LOOH}+\mathrm{zNOx}+\mathrm{zAOPP}$. We also used two other $\mathrm{z}$ unit weighted composite scores, namely, zSOD+LOOH and zLOOH+AOPP as indices of superoxide and hydryxyperoxide formation, and lipid + protein oxidation, respectively [12].

MDA levels were measured through complexation with two molecules of thiobarbituric acid (TBA) using MDA estimation through high-performance liquid chromatography (HPLC Alliance e2695, Waters', Barueri, SP, Brazil) [55]. Experimental conditions included the use of a column Eclipse XDB-C18 (Agilent, USA); the mobile phase consisted of $65 \%$ phosphate buffer $(50 \mathrm{nM} \mathrm{pH} \mathrm{7.0)}$ and $35 \%$ HPLC grade methanol; the flow rate was $1.0 \mathrm{~mL} / \mathrm{minute}$; the temperature was $30{ }^{\circ} \mathrm{C}$; the wavelength was $532 \mathrm{~nm}$. MDA concentration in the samples was quantified based on a calibration curve and are expressed in mmol of MDA/mg proteins. HDL cholesterol was measured with an enzymatic colorimetric method in an automated clinical chemistry system (Dimension RXL, Siemens, USA). PON1 status was measured using different kinetic assays conducted in a microplate reader (EnSpire, Perkin Elmer, USA) [26]. The substrate phenylacetate (PA, Sigma, USA) under a high salt condition and 4-(chloromethyl)phenyl acetate (CMPA, Sigma, USA) were used. PON1 total activity was determined by the rate of hydrolysis of phenyl acetate under a low salt condition at $270 \mathrm{~nm}$ and $25{ }^{\circ} \mathrm{C}$. The activity was expressed in U/mL based on the phenyl acetate molar extinction coefficient of $1.31 \mathrm{mmol} / \mathrm{L} \mathrm{cm}-1$. In the present study, we adjusted PON1 and CMPAase activities for the PON1 genotypes and used the residualized values in subsequent analyses.

Uric acid was measured with an UV enzymatic method (direct equilibrium uricase method) in an automated clinical chemistry system (Dimension RXL, Siemens, USA). hsCRP was assayed using a nephelometric assay (Behring Nephelometer II, Dade Behring, Marburg, Germany). The interassay coefficients of variability were less than $10 \%$. The ARCHITECT TSH assay is a Chemiluminescent Microparticle Immunoassay (CMIA). The analytical measuring range for the Abbott Architect TSH assay was 0.01 to $80.00 \mu \mathrm{IU} / \mathrm{L}$ and the intra-assay CV values were $<2.6 \%$. HDL-cholesterol was assayed by automated methods using the DimensionRxL (Deerfield, IL, USA). Plasma insulin levels were determined with a microparticle enzyme immunoassay (MEIA) (AXSYM, Abbotts Laboratory, Germany). Glucose was assayed using an automated method in a clinical chemistry system, Dimension ${ }^{\circledR}$ RXL (Siemens Healthcare Diagnostics Inc, USA). The interassay $\mathrm{CV}$ values for all analytes were $<10 \%$. 


\section{Statistics}

We used analysis of contingency tables $\left(\chi^{2}\right.$-test) to check associations between nominal variables. Analysis of variance (ANOVA) was employed to assess differences in scale variables between groups. Pearson's product moment or Spearman's rank order coefficients were used to examine associations between scale variables, and the point-biserial correlation coefficients were used to examine associations between binary (e.g., sex) and scale variables. All tests were twotailed and an alpha level of 0.05 was considered to be statistically significant. All analyses were performed using the IMB-SPSS software version 24 for Windows.

Partial least squares analysis (SmartPLS) was used as a path modeling technique with PLSstructural equation modeling algorithms [56]. We examined the effects of new staging constructs or latent vectors (LVs) (used as input variables) on affective phenomenology (output variables). Some variables were introduced in the path model as single indicators (e.g., income, age or sex), while others were used as LVs extracted from a set of indicator variables in a reflective model (e.g., total scores on the WHO-QoL and Sheehan reflecting QoL and disabilities). PLS path analysis was only performed when the model and constructs complied with specific quality criteria, namely: (a) model fit standardized root mean residual (SRMR) < 0.08; (b) composite constructs had good discriminant validity and reliability as indicated by average variance extracted $(\mathrm{AVE})>0.45$ and composite reliability $>0.700$; and (c) construct cross-validated redundancies and communalities were checked [56]. Consequently, we performed consistent PLS bootstrapping with 2000 bootstraps and computed path coefficients with t-values and exact $p$-values for the inner model and t-values and loadings on the LVs for the outer model. In addition, we interpreted the total effects, total indirect and specific indirect effects. Finally, a newly constructed LV was only accepted as valid when it showed a composite reliability $>0.800$, Cronbach's alpha $>0.75$, rho_A $>0.8$ and AVE $>0.450$. Indicators were only included in LVs when the factor loadings were $>$ 0.45 with $\mathrm{p}<0.01$.

\section{Results}

1. Construction of a recurrence index based on the recurrence of episodes and suicidal behaviors.

Figure 1 shows a first attempt to construct a new relapse index based on the recurrence of episodes and suicidal behaviors. Table 1 shows that the reliability characteristics of the first LV extracted from the number of all episodes, number of depression episodes, number of suicide attempts and lifetime suicidal ideation (the "recurrence-LV") performed well as a composite score with an adequate composite reliability, Cronbach's alpha and rho_A and AVE. The number of all episodes (0.849), number of depression episodes (0.917), number of suicide attempts $(0.693)$ and lifetime suicidal ideation (0.721) loaded highly on this recurrence LV. The number of (hypo)maniac episodes could be considered as a valid fifth indicator of this recurrence LV, because its use caused considerable collinearity in the subsequent analyses. Therefore, we did not incorporate this indicator variable in the "recurrence LV". 
Table 1. Construct reliability and validity of the 5 staging indices constructed in the current study.

\begin{tabular}{|l|l|l|l|l|l|}
\hline $\begin{array}{l}\text { Construct reliability } \\
\text { measures }\end{array}$ & $\begin{array}{l}\text { Recurrence } \\
\text { index }\end{array}$ & $\begin{array}{l}\text { Staging } \\
\text { index }\end{array}$ & $\begin{array}{l}\text { ELT-Staging } \\
\text { HOC }\end{array}$ & $\begin{array}{l}\text { Final ELT- } \\
\text { Staging } \\
\text { index }\end{array}$ & $\begin{array}{l}\text { PON1- } \\
\text { Staging } \\
\text { index }\end{array}$ \\
\hline Composite reliability & 0.875 & 0.892 & 0.906 & 0.902 & 0.861 \\
\hline Cronbach $\alpha$ & 0.807 & 0.849 & 0.885 & 0.879 & 0.797 \\
\hline Rho_A & 0.821 & 0.863 & 0.899 & 0.887 & 0.815 \\
\hline $\begin{array}{l}\text { Average variance } \\
\text { extracted }\end{array}$ & 0.640 & 0.512 & 0.454 & 0.460 & 0.513 \\
\hline
\end{tabular}

ELT: Early Life Trauma

HOC: higher order construct

PON1: paraoxonase 1

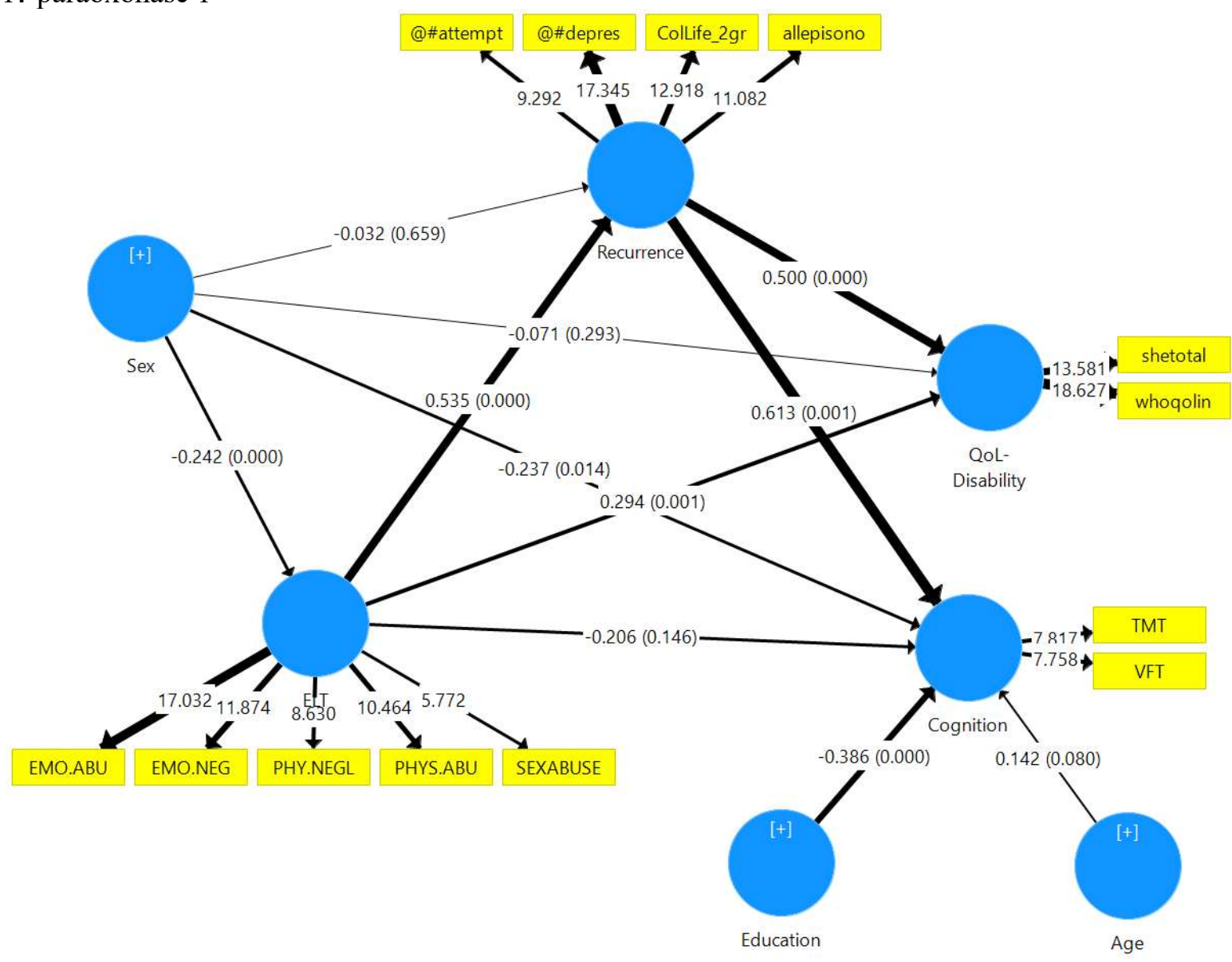

Figure 1. Results of consistent partial least squares (PLS) bootstrapping (2000 bootstraps) showing the "recurrence staging index" and predicting outcome measurements including a "QoLDisability" latent vector (LV) extracted from health-related quality of life (whoqolin) and the Sheehan total score (shetotal) and a "cognition" LV extracted from the trail making test (TMT) and verbal fluency test (VFT) scores. Education and age are additional explanatory variables. The recurrence staging index is predicted by an "early lifetime trauma" (ELT) LV extracted from 5 ELT scores, namely emotional abuse (emo.abu), emotional neglect (emo.neg), physical neglect 
(phy.negl), physical abuse (phys.abu) and sexual abuse (sexabuse), which, in turn, is predicted by sex. The model shows path coefficients and exact $p$-values for the inner model and $t$ values for the outer model.

Figure 1 shows the first PLS path model using a "Qol-disability LV" (extracted from the total Sheehan and WHO-QoL scores as indicators) and a "cognitive LV" (extracted from TMT and VFT as indicator variables) as output variables. Input variables were the "recurrence LV", an "ELT LV" (extracted from the 5 ELTs as indicators) and sex (male=1, female=0). Sex and the ELT LV were introduced in the model as explanatory variables for the recurrence LV, while sex was also an explanatory variable for the ELT LV. Thus, this model also examined whether the effects of ELT on the outcome variables were mediated by the recurrence LV. Figure 1 shows the outcome of consistent PLS bootstrapping (2000 bootstraps) with path coefficients and exact pvalues for the inner model and $t$ values for the outer model. Since the cognitive tests were performed in a subset, we carried out the analysis using the mean replacement method, although casewise deletion showed essentially the same results. The model quality data were very adequate with a model fit SRMR $=0.052$, composite reliabilities (for ELT LV $=0.856$ and QoL-disability $\mathrm{LV}=0.831$, Cronbach's alpha (for ELT LV $=0.848$ and QoL-disability LV $=0.817$ ), rho_A values (for ELT LV $=0.881$ and QoL-disability LV $=0.856$ ) and AVE values (for ELT LV $=0.551$ and QoL-disability LV $=0.714$ ).

We found that $52.6 \%$ of the variance in the QoL-Disability LV was explained by the recurrence LV and ELT LV, and $25.1 \%$ of the variance in the cognitive LV was explained by the recurrence LV, sex and education. We found that $30.0 \%$ of the variance in the recurrence LV was explained by the ELT LV, which in turn was associated with female sex. There were significant total effects of sex on ETL-LV $(\mathrm{t}=-2.57, \mathrm{p}=0.011)$, Qol-Disability LV $(\mathrm{t}=-3.18, \mathrm{p}=0.002)$, recurrence $\operatorname{LV}(\mathrm{t}=-3.06, \mathrm{p}=0.002)$ and cognitive $\mathrm{LV}(\mathrm{t}=-2.53, \mathrm{p}=0.012)$. There were significant total effects of ELT LV on QoL-Disability LV $(\mathrm{t}=5.81, \mathrm{p}<0.001)$ and there was a significant specific indirect effect of sex on the recurrence LV mediated by ELT-LV $(t=-2.07, p=0.039)$. There were significant indirect effects of ELT-LV on QoL-Disability LV $(t=2.52, p=0.012)$ and cognitive $\operatorname{LV}(\mathrm{t}=2.50, \mathrm{p}=0.013)$.

2. Associations between the recurrence index and affective phenomenology.

Figure 2 shows a second PLS path model using the recurrence LV as an input variable and different characteristics of affective phenomenology as output variables, including income, a drug LV (extracted from use of antipsychotics, lithium and anticonvulsant mood stabilizers as indicators), severity of current suicidal ideation, YMRS, a severity LV extracted from the HAMD and HAM-A scores, BMI-MetS LV (extracted from BMI and MetS as indicators), an antioxidant LV (extracted from CMPAAse, HDL-cholesterol and PON1 values), an O\&NS LV (extracted from zLOOH+AOPP, zSOD+LOOH and zSOD+LOOH+NOx+AOPP) and UA, hsCRP, basal TSH and HOMA-IR as single indicators. The BMI-MetS LV was introduced as an explanatory variable for all biomarker data. Thus, this model also examined whether the effects of the recurrence LV on biomarker data were (partly) mediated by the BMI-MetS LV. 


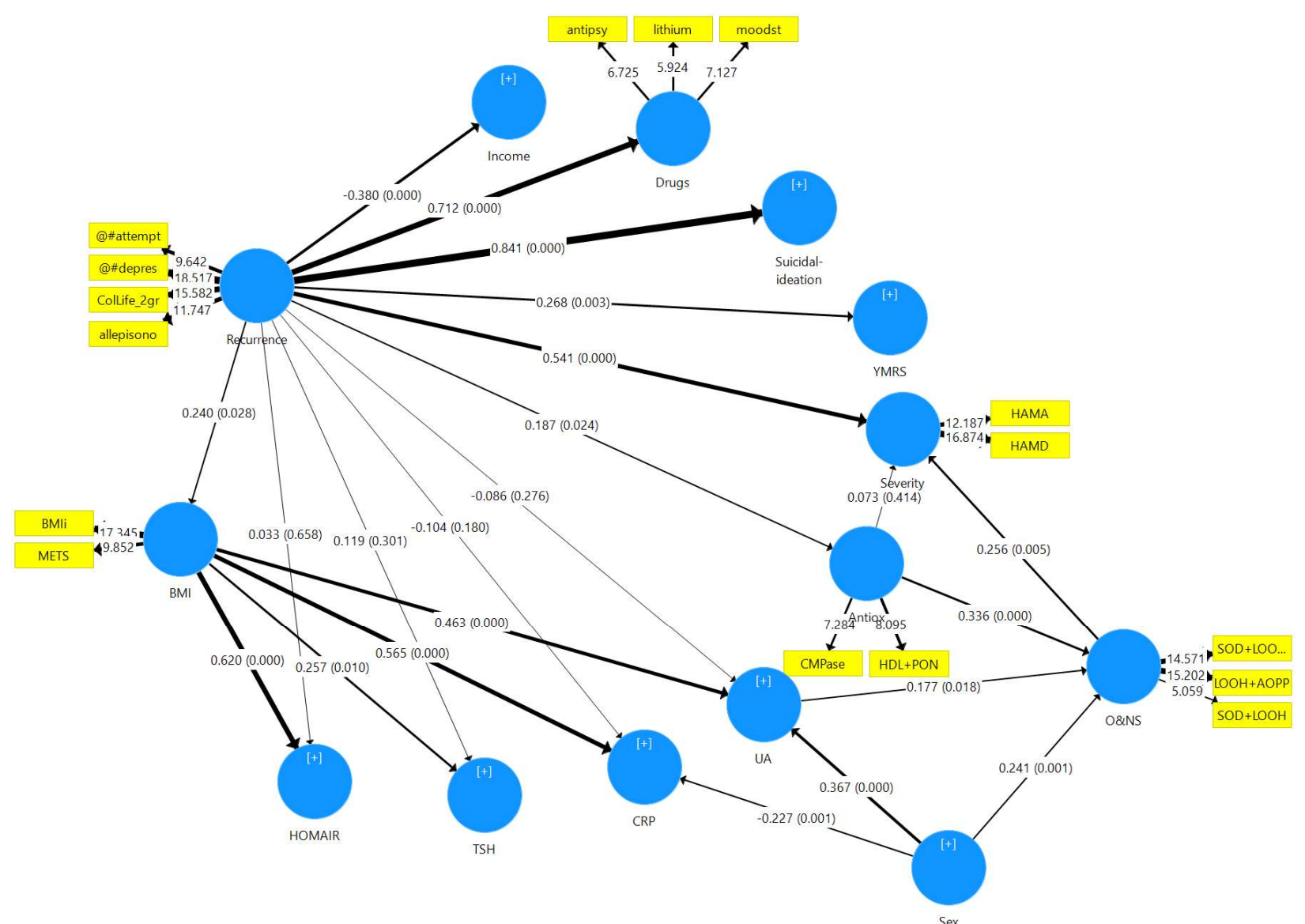

Figure 2. Results of consistent partial least squares (PLS) bootstrapping (2000 bootstraps) showing the "recurrence staging index" latent vector (LV) (see legends to Figure 1) predicting income, a "drugs" LV (extracted from use of antipsychotics (antipsy), lithium and mood stabilizers (moodst)), current suicidal ideation, Young Mania Rating Scale (YMRS), a "severity" LV (extracted from the Hamilton Depression (HAMD) and anxiety (HAMA) Rating Scale scores), an "antioxidant" LV (antiox) (extracted from PON1 activities and HDL-cholesterol) and a "body mass index" (BMI) LV (extracted from BMI and metabolic syndrome (METS)). The latter predicts biomarkers, including uric acid (UA), C-reactive protein (CRP), thyroid stimulating hormone (TSH) and a HOMA-insulin resistance index (HOMAIR). The antiox LV and UA predict the oxidative and nitrosative (O\&NS) LV (extracted from the three O\&NS biomarker scores used in the present study). Sex predicts UA, CRP and O\&NS LV. The model shows path coefficients and exact $\mathrm{p}$-values for the inner model and $\mathrm{t}$ values for the outer model.

Figure 2 shows the outcome of consistent PLS bootstrapping (2000 bootstraps). The model quality data were very adequate with model fit $\mathrm{SRMR}=0.065$, composite reliabilities that were $>$ 0.803 for all LVs (antioxidant, O\&NS, BMI-MetS, drugs, severity LVs and of course the recurrence LV) and with AVE values that were $>0.577$ for all LVs. We found that the recurrence LV explained a large part of the variance in the severity LV (38.5\%), YMRS (7.2\%), the drug LV $(50.7 \%)$, income $(14.4 \%)$ and suicidal ideation $(70.8 \%)$, while $5.8 \%$ of the variance in the BMIMetS LV and $3.5 \%$ of the variance in the antioxidant LV was explained by the recurrence LV. There were no significant direct effects of the recurrence LV on UA, hsCRP, basal TSH and HOMA-IR index. There were significant associations between the BMI-MetS LV and hsCRP, 
HOMA-IR index, basal TSH and UA. There were significant specific indirect effects of the recurrence LV on hsCRP $(\mathrm{t}=2.06, \mathrm{p}=0.040)$ and HOMA-IR $(\mathrm{t}=2.15, \mathrm{p}=0.032)$, which were mediated by the BMI-MetS LV. There were no significant effects of the recurrence and BMI-MetS LVs on the O\&NS LV, while O\&NS was affected by the antioxidant LV and UA and predicted an increased severity LV. There were significant direct effects of the antioxidant LV and UA on the O\&NS LV, which in turn showed direct effects on the severity LV. There were significant total effects of sex on hsCRP, O\&NS and UA.

3. Associations between a staging index and affective phenomenology.

Figure 3 shows the results of a third PLS analysis with the construction of a second staging index, based on the 4 indicators used in the recurrent LV, combined with the outcome variables in Figure 1, namely, Sheehan total and WHOQoL scores as well as cognitive test results, namely, VFT and TMT_A (TMT_B could not be combined). Table 1 shows that the LV extracted from these indicators had very good performance with excellent composite reliability, Cronbach's $\alpha$, rho_A and AVE. All loadings of the 8 indicators were $>0.484$, all at $\mathrm{p}<0.001$. The PLS model in Figure 3 examines this second staging index as an output variable using the ELT LV as direct explanatory variable and sex as an explanatory variable for both the ELT and staging LV. Figure 3 shows the path model computed using consistent PLS bootstrapping (2000 bootstraps) with casewise deletion. The ELT LV quality data were very adequate with composite reliability of 0.903 , Cronbach's $\alpha$ of 0.866 , rho_A of 0.908 and AVE of 0.655 . We found that $39.6 \%$ of the variance in the staging LV was explained by the regression on the ELT LV (sex was not significant) and that sex explained $8.3 \%$ of the variance in the ELT LV. There was a significant specific indirect effect of sex on the staging LV mediated by ELT LV $(\mathrm{t}=-2.23, \mathrm{p}=0.026)$.

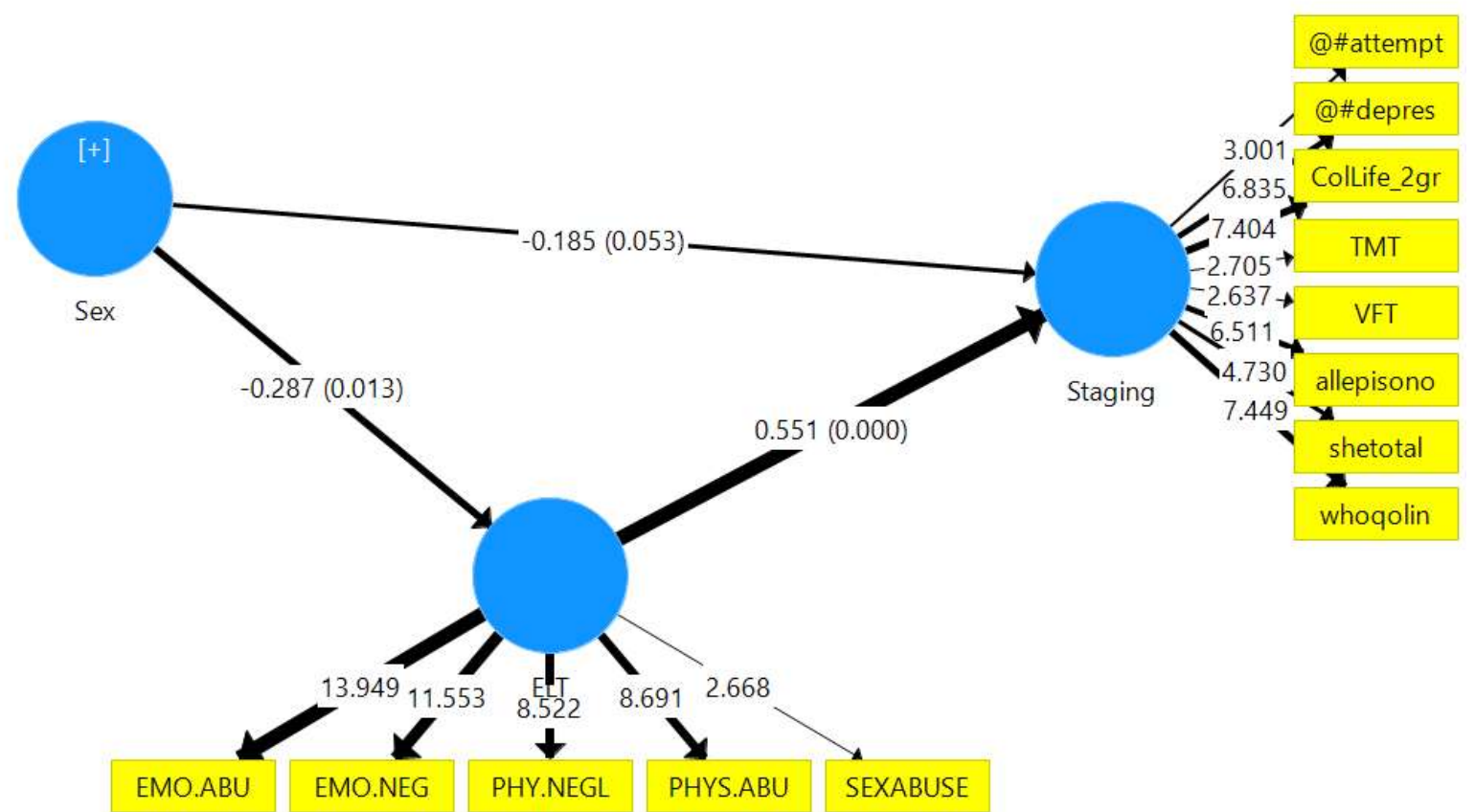

Figure 3. Results of consistent partial least squares (PLS) bootstrapping (2000 bootstraps) showing the construction of a "staging index" latent vector (LV). This staging index consists of number of 
previous suicide attempts (@\#attempt), lifetime suicidal ideation (ColLife_2gr), number of depressive (@\#depres) and total number of episodes (allepisono), Sheehan total score (shetotal), WHO-QoL total score (whoqolin), trail making test (TMT) and verbal fluency test (VFT) scores. This staging index is predicted by an "early lifetime trauma" (ELT) LV extracted from 5 ELT scores, namely emotional abuse (emo.abu), emotional neglect (emo.neg), physical neglect (phy.negl), physical abuse (phys.abu) and sexual abuse (sexabuse), which, in turn, is predicted by sex. The model shows path coefficients and exact $p$-values for the inner model and $t$ values for the outer model.

This second staging index was strongly correlated with the recurrence LV $(\mathrm{r}=0.915$, $\mathrm{p}<0.001, \mathrm{n}=172)$ and education $(\mathrm{r}=-0.316, \mathrm{p}<0.001, \mathrm{n}=171)$, income $(\mathrm{r}=-0.452, \mathrm{p}<0.001, \mathrm{n}=170)$, employment status $(\mathrm{r}=-0.376, \mathrm{p}<0.001, \mathrm{n}=171)$, severity LV $(\mathrm{r}=0.635, \mathrm{p}<0.001, \mathrm{n}=172)$, YMRS $(\mathrm{r}=0.283, \mathrm{p}<0.001, \mathrm{p}=172)$, severity of current suicidal ideation $(\mathrm{r}=0.491, \mathrm{p}<0.001, \mathrm{n}=172)$, CGI score $(\mathrm{r}=0.531, \mathrm{p}<0.001, \mathrm{n}=169)$, the drug LV $(\mathrm{r}=0.514, \mathrm{p}<0.001, \mathrm{n}=172)$, and the BMI-MetS LV $(\mathrm{r}=0.187, \mathrm{p}=0.014, \mathrm{n}=172)$.

\section{Construction of the ELT-staging index.}

Figure 4 shows how we made a higher order construct (named ELT-staging HOC), based on the five ELTs and all indicators of the staging LV presented in Table 3, by combining all indicators of the ELT LV and the staging LV into one HOC comprising 13 indicators. The AVE was, however, only 0.424 and the loading of TMT_A on this LV was only 0.345 . Therefore, we deleted TMT_A from this analysis and reran the PLS analysis. Table 1 shows that the LV extracted from those $1 \overline{2}$ indicators (thus without TMT_A) performed well and showed good composite reliability, Cronbach's $\alpha$ and rho_A, with an AVE of 0.454 . All variables loaded significantly on this latent vector, namely, all $>0.451$ and all $\mathrm{p}<0.001$. 


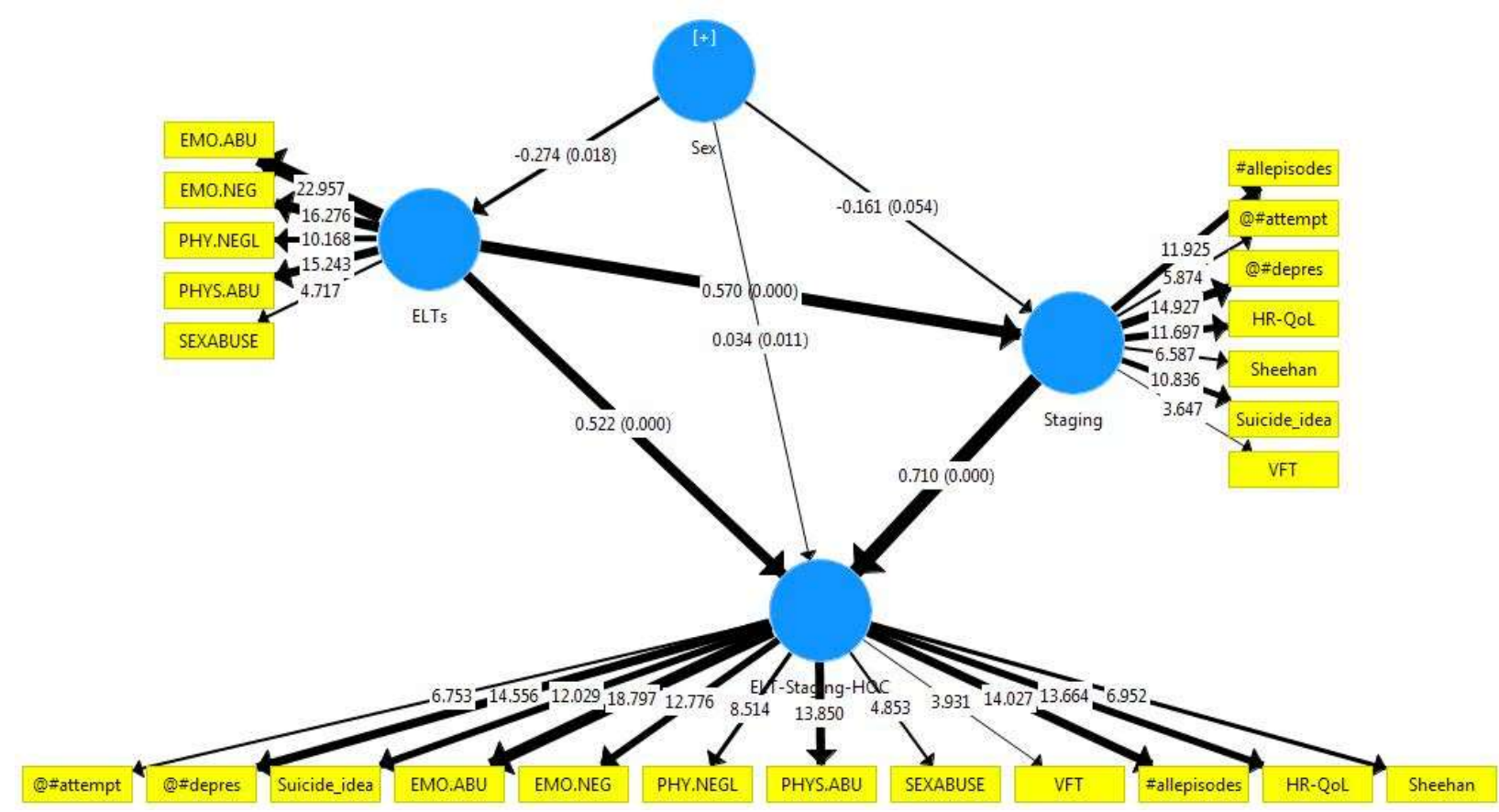

Figure 4. Results of consistent partial least squares (PLS) bootstrapping (2000 bootstraps) showing the construction of an "ELT staging HOC" (higher order construct) using all indicators of the early lifetime trauma (ELT) latent vector (LV) (see Figure 1 for description) and the "staging index" LV (see Figure 3 for description). This ELT staging HOC index consists of number of previous suicide attempts (@\#attempt), lifetime suicidal ideation (ColLife_2gr), number of depressive (@\#depres) and total number of episodes (allepisono), Sheehan total score (shetotal), WHO-QoL total score (whoqolin), verbal fluency test (VFT) score, and 5 ELT scores, namely emotional abuse (emo.abu), emotional neglect (emo.neg), physical neglect (phy.negl), physical abuse (phys.abu) and sexual abuse (sexabuse). The model shows path coefficients and exact p-values for the inner model and $t$ values for the outer model.

Table 3. Socio-demographic and clinical characteristics of the three staging groups based on the final ELT-staging index

\begin{tabular}{|l|l|l|l|l|l|l|l|}
\hline Variables & $\begin{array}{l}\text { Controls } \\
\left(\mathbf{n = 6 7 ) ^ { \mathbf { A } }}\right.\end{array}$ & $\begin{array}{l}\text { Stage 1 } \\
(\mathbf{n = 3 5})^{\mathbf{B}}\end{array}$ & $\begin{array}{l}\text { Stage 2 } \\
(\mathbf{n = 3 5})^{\mathbf{C}}\end{array}$ & $\begin{array}{l}\text { Stage 3 } \\
(\mathbf{n = 3 5})^{\mathbf{D}}\end{array}$ & $\mathbf{F}$ & $\mathbf{d f}$ & $\mathbf{P}$ \\
\hline Age (years) & $43.1(11.6)$ & $\begin{array}{l}43.9 \\
(12.1)\end{array}$ & $42.3(11.0)$ & $41.8(9.3)$ & 0.25 & $3 / 168$ & 0.865 \\
\hline Sex (F/M) & $44 / 23^{\mathrm{C}}$ & $23 / 12$ & $32 / 3^{\mathrm{A}}$ & $30 / 5$ & 11.90 & 3 & 0.008 \\
\hline Marital status \# & $16 / 40 / 11$ & $11 / 18 / 6$ & $6 / 21 / 8$ & $5 / 18 / 12$ & 7.15 & 6 & 0.307 \\
\hline Education (years) & $\begin{array}{l}12.6(5.6)^{\mathrm{B}}, \\
\mathrm{D}\end{array}$ & $\begin{array}{l}10.1(5.5) \\
\mathrm{A}\end{array}$ & $11.1(4.2)$ & $9.5(4.3)^{\mathrm{A}}$ & 3.53 & $3 / 167$ & 0.016 \\
\hline
\end{tabular}




\begin{tabular}{|c|c|c|c|c|c|c|c|}
\hline Income & $\begin{array}{l}3.82(1.29) \\
C, D\end{array}$ & $\begin{array}{l}3.56 \\
(1.13)^{\mathrm{D}}\end{array}$ & $\begin{array}{l}2.97(1.45) \\
\text { A }\end{array}$ & $\begin{array}{l}2.54(1.58) \\
\mathrm{A}, \mathrm{B}\end{array}$ & 7.91 & $3 / 166$ & $<0.001$ \\
\hline Employment (N/Y) & $14 / 52^{\mathrm{C}, \mathrm{D}}$ & $12 / 23^{\mathrm{C}}$ & $25 / 10^{\mathrm{A}, \mathrm{B}}$ & $22 / 13^{\mathrm{A}}$ & 31.09 & 3 & $<0.001$ \\
\hline HAM-D & $2.8(3.7) *$ & $6.5(5.6) *$ & $\begin{array}{l}11.8(6.3) \\
\mathrm{A}, \mathrm{B}\end{array}$ & $\begin{array}{l}11.5(6.4) \\
\mathrm{A}, \mathrm{B}\end{array}$ & 31.32 & $3 / 168$ & $<0.001$ \\
\hline HAM-A & $6.7(7.8)^{\mathrm{C}, \mathrm{D}}$ & $\begin{array}{l}10.2(7.8) \\
\mathrm{C}, \mathrm{D}\end{array}$ & $\begin{array}{l}17.6(10.7) \\
\mathrm{A}, \mathrm{B}\end{array}$ & $\begin{array}{l}17.4(9.6) \\
\mathrm{A}, \mathrm{B}\end{array}$ & 16.10 & $3 / 157$ & $<0.001$ \\
\hline YMRS & $1.1(2.5)^{\mathrm{C}}$ & $\begin{array}{l}0.8 \\
(1.4)^{\mathrm{C}, \mathrm{D}}\end{array}$ & $\begin{array}{l}2.2(2.9) \\
\text { A,B }\end{array}$ & $2.0(2.8)^{\mathrm{B}}$ & 3.04 & $3 / 168$ & 0.031 \\
\hline $\begin{array}{l}\text { Duration of illness } \\
\text { (years) }\end{array}$ & - & 15.713 .2 & 17.811 .0 & 19.811 .8 & 0.89 & $2 / 92$ & 0.416 \\
\hline CGI & $2.32(1.55) *$ & $\begin{array}{l}3.32 \\
(1.20) * \\
\end{array}$ & $\begin{array}{l}4.00(1.16) \\
A, B\end{array}$ & $\begin{array}{l}4.00(1.26) \\
A, B\end{array}$ & 17.50 & $3 / 165$ & $<0.001$ \\
\hline $\begin{array}{l}\text { Current suicidal } \\
\text { ideation }(\mathrm{N} / \mathrm{Y})\end{array}$ & $0.18(0.67)$ & $\begin{array}{l}1.54 \\
(1.96) \\
A, D\end{array}$ & $\begin{array}{l}1.86 \\
(1.94) \text { A,D }\end{array}$ & $\begin{array}{l}3.74 \\
(1.79) *\end{array}$ & 69.73 & 3 & $<0.001$ \\
\hline $\mathrm{BMI}\left(\mathrm{kg} / \mathrm{m}^{2}\right)$ & $26.3(4.7)^{\mathrm{D}}$ & $\begin{array}{l}24.8(3.9) \\
D\end{array}$ & $26.6(4.9)$ & $\begin{array}{l}28.6(5.4) \\
\mathrm{A}, \mathrm{B}\end{array}$ & 3.72 & $3 / 161$ & 0.013 \\
\hline $\begin{array}{l}\text { Metabolic Syndrome } \\
(\mathrm{N} / \mathrm{Y})\end{array}$ & $40 / 26$ & $25 / 10$ & $21 / 14$ & $20 / 15$ & 1.75 & 3 & 0.618 \\
\hline $\begin{array}{l}\text { Antidepressants } \\
(\mathrm{N} / \mathrm{Y})\end{array}$ & - & $22 / 12$ & $18 / 16$ & $19 / 16$ & 1.56 & 2 & 0.561 \\
\hline $\begin{array}{l}\text { Mood stabilizers } \\
(\mathrm{N} / \mathrm{Y})\end{array}$ & - & $30 / 4^{D}$ & $22 / 12$ & $18 / 17^{\mathrm{B}}$ & 10.98 & 2 & 0.004 \\
\hline Lithium (N/Y) & - & $29 / 5$ & $26 / 8$ & $22 / 13$ & 4.68 & 2 & 0.096 \\
\hline $\begin{array}{l}\text { Antipsychotics } \\
(\mathrm{N} / \mathrm{Y})\end{array}$ & - & $27 / 7$ & $24 / 10$ & $20 / 15$ & 4.06 & 2 & 0.131 \\
\hline $\mathrm{BP} 1 / \mathrm{BP} 2 / \mathrm{MDD}$ & - & $7 / 7 / 21^{\mathrm{C}, \mathrm{D}}$ & $20 / 8 / 7^{\mathrm{B}}$ & $18 / 8 / 9^{\mathrm{B}}$ & 15.92 & 4 & 0.003 \\
\hline
\end{tabular}

\# Marital status: single / married / separated

HAM-D: Hamilton Depression Rating Scale

HAM-A: Hamilton Anxiety Rating Scale

YMRS: Young Mania Rating Scale

CGI: Clinical Global Impression

BMI: body mass index

BP1/BP2/MDD: bipolar type 1, bipolar type 2, major depressive disorder

For reasons of simplicity, we calculated a final model without TMT_A and VFT. Table 1 shows that the LV extracted from these 11 indicators (Final ELT-staging index) had very good performance with excellent composite reliability, Cronbach's $\alpha$ and rho_A and a sufficient AVE, namely, 0.460. All indicators loaded highly on this LV; all loadings were $>0.512$ and all $\mathrm{p}<0.001$. There was a very strong association between this index and the ELT-staging-HOC $(\mathrm{r}=0.995$, $\mathrm{p}<0.001, \mathrm{n}=172)$. There were significant direct effects of sex on the recurrence-staging $(\mathrm{t}=-3.52$, $\mathrm{p}<0.001)$ and ELT-staging HOC $(\mathrm{t}=-3.39, \mathrm{p}<0.001)$ indices. 
5. Characteristics of the staging groups.

We used the final ELT staging index as a reference staging index and applied the 66.6666 and 33.3333 percentile values to divide the patients into 3 groups with equal numbers, thus reflecting three different stages of illness. Table 2 shows the staging indices computed here (namely, recurrence index, staging index, ELT-staging HOC, and the final ELT staging index), as well as the recurrence indicators, total WHOQoL and Sheehan scores, TMT and VFT values in these three staging groups compared with controls. The staging indices were significantly different among the 4 groups and increased in the order of controls $\rightarrow$ stage $1 \rightarrow$ stage $2 \rightarrow$ stage 3 . The number of depressive episodes and total number of episodes were significantly different between the 3 staging groups and increased in the order of stage $1 \rightarrow$ stage $2 \rightarrow$ stage 3 . The number of suicidal attempts and lifetime suicidal ideation were significantly greater in stage 3 compared with all other groups, while lifetime suicidal ideation was also significantly more prevalent in stages 1 and 2 than in controls. The Sheehan and WHO-QoL scores were significantly different between stages 2 and 3 and the other two groups. VFT was significantly lower in the mood staging groups compared with controls, while TMT_A was significantly higher in stages $2 / 3$ than in controls, and there was a trend towards higher TMT_B in stage 3 compared with controls. All five ELTs showed significant differences between the groups with higher values in stage 3 than in all other groups and higher values in stage 2 than in stage 1.

Table 2. Measurement of the indicator variables in controls and three staging groups based on the final ELT-staging index

\begin{tabular}{|c|c|c|c|c|c|c|c|}
\hline Variables & $\begin{array}{l}\text { Controls } \\
(\mathbf{n}=67)^{A}\end{array}$ & $\begin{array}{l}\text { Stage 1 } \\
(\mathrm{n}=35)^{B}\end{array}$ & $\begin{array}{l}\text { Stage 2 } \\
(n=35)^{C}\end{array}$ & $\begin{array}{l}\text { Stage } 3 \\
(\mathrm{n}=35) \mathrm{D}\end{array}$ & $\mathbf{F}$ & df & $\mathbf{P}$ \\
\hline Recurrence index & $\begin{array}{l}-0.768 \\
(0.379) *\end{array}$ & $\begin{array}{l}-0.153 \\
(0.573) *\end{array}$ & $\begin{array}{l}0.324 \\
(0.615) *\end{array}$ & $\begin{array}{l}1.301 \\
(1.016) *\end{array}$ & 84.28 & $3 / 168$ & $<0.001$ \\
\hline Staging index & $\begin{array}{l}-0.859 \\
(0.410) *\end{array}$ & $\begin{array}{l}-0.205 \\
(0.390) *\end{array}$ & $\begin{array}{l}0.557 \\
(0.445) *\end{array}$ & $\begin{array}{l}1.293 \\
(0.914) *\end{array}$ & 130.18 & $3 / 168$ & $<0.001$ \\
\hline $\begin{array}{l}\text { ELT-Staging } \\
\text { HOC }\end{array}$ & $\begin{array}{l}-0.783 \\
(0.482) *\end{array}$ & $\begin{array}{l}-0.460 \\
(0.284) *\end{array}$ & $\begin{array}{l}0.421 \\
(0.302) *\end{array}$ & $\begin{array}{l}1.538 \\
(0.628) *\end{array}$ & 222.93 & $3 / 168$ & $<0.001$ \\
\hline $\begin{array}{l}\text { Final ELT- } \\
\text { Staging index }\end{array}$ & $\begin{array}{l}-0.774 \\
(0.469) *\end{array}$ & $\begin{array}{l}-0.498 \\
(0.273) *\end{array}$ & $\begin{array}{l}0.428 \\
(0.311) *\end{array}$ & $\begin{array}{l}1.551 \\
(0.597) *\end{array}$ & 240.12 & $3 / 168$ & $<0.001$ \\
\hline $\begin{array}{l}\text { PON1-staging } \\
\text { index }\end{array}$ & $\begin{array}{l}-0.821 \\
(0.531) *\end{array}$ & $\begin{array}{l}-0.174 \\
(0.425) *\end{array}$ & $\begin{array}{l}0.632 \\
(0.696) *\end{array}$ & $\begin{array}{l}1.113 \\
(0.894) *\end{array}$ & 84.66 & $3 / 168$ & $<0.001$ \\
\hline $\begin{array}{l}\text { \# Depressive } \\
\text { episodes }\end{array}$ & - & $\begin{array}{l}2.41(2.31) \\
*\end{array}$ & $\begin{array}{l}4.41(3.34) \\
*\end{array}$ & $\begin{array}{l}8.50(5.36) \\
*\end{array}$ & 21.71 & $2 / 99$ & $<0.001$ \\
\hline $\begin{array}{l}\text { \#Hypomanic } \\
\text { episodes }\end{array}$ & - & $\begin{array}{l}1.74 \text { (2.98) } \\
*\end{array}$ & $\begin{array}{l}6.67(1.13) \\
\text { B }\end{array}$ & $\begin{array}{l}7.30(1.23) \\
\text { B }\end{array}$ & 5.48 & $2 / 102$ & 0.005 \\
\hline \# Total episodes & - & $\begin{array}{l}4.21(4.88) \\
*\end{array}$ & $\begin{array}{l}9.68(7.47) \\
*\end{array}$ & $\begin{array}{l}14.97 \\
(10.42) *\end{array}$ & 15.70 & $2 / 99$ & $<0.001$ \\
\hline $\begin{array}{l}\text { \# Suicidal } \\
\text { attempts }\end{array}$ & $\begin{array}{l}0.01(0.036) \\
D\end{array}$ & $\begin{array}{l}0.29(0.71) \\
D\end{array}$ & $\begin{array}{l}0.86(1.57) \\
D\end{array}$ & $\begin{array}{l}4.17 \text { (5.44) } \\
*\end{array}$ & 21.35 & $3 / 168$ & $<0.001$ \\
\hline
\end{tabular}




\begin{tabular}{|c|c|c|c|c|c|c|c|}
\hline $\begin{array}{l}\text { Lifetime suicidal } \\
\text { ideation }\end{array}$ & $53 / 8^{*}$ & $15 / 20^{\mathrm{A}, \mathrm{D}}$ & $11 / 24^{\mathrm{A}, \mathrm{D}}$ & $1 / 34 *$ & 69.73 & 3 & $<0.001$ \\
\hline Sheehan score & $3.96(7.34) *$ & $\begin{array}{l}8.29(8.14) \\
*\end{array}$ & $\begin{array}{l}18.14 \\
(7.87)^{\mathrm{A}, \mathrm{B}}\end{array}$ & $\begin{array}{l}18.71 \\
(8.10)^{\mathrm{A}, \mathrm{B}}\end{array}$ & 41.03 & $3 / 167$ & $<0.001$ \\
\hline HR-QoL score & $95.6(11.6) *$ & $\begin{array}{l}87.9(10.1) \\
*\end{array}$ & $\begin{array}{l}71.3(12.5) \\
\mathrm{A}, \mathrm{B}\end{array}$ & $\begin{array}{l}66.5(12.0) \\
\mathrm{A}, \mathrm{B}\end{array}$ & 63.60 & $3 / 167$ & $<0.001$ \\
\hline $\begin{array}{l}\text { Verbal Fluency } \\
\text { Test }\end{array}$ & $17.6(4.8) *$ & $12.7(3.7)^{\mathrm{A}}$ & $13.9(2.2)^{\mathrm{A}}$ & $13.1(4.3)^{\mathrm{A}}$ & 7.70 & $3 / 79$ & $<0.001$ \\
\hline $\begin{array}{l}\text { Trail Making } \\
\text { Test, part A }\end{array}$ & $\begin{array}{l}40.8 \text { (19.9) } \\
\text { c,D }\end{array}$ & $50.6(37.7)$ & $53.2(18.3)^{\mathrm{A}}$ & $68.5(62.6)$ & 3.48 & $3 / 80$ & 0.020 \\
\hline $\begin{array}{l}\text { Trail making } \\
\text { Test, part B }\end{array}$ & $127(100)^{\mathrm{D}}$ & $158(104)$ & $171(106)$ & $190(133)$ & 2.20 & $3 / 79$ & 0.095 \\
\hline Sexual abuse & $\begin{array}{l}5.37(1.52) \\
\mathrm{C,D}\end{array}$ & $\begin{array}{l}5.26(1.12) \\
\mathrm{C}, \mathrm{D}\end{array}$ & $\begin{array}{l}7.23(3.12) \\
*\end{array}$ & $\begin{array}{l}9.00(5.65) \\
*\end{array}$ & 12.20 & $3 / 168$ & $<0.001$ \\
\hline Physical abuse & $7.19(3.47)^{\mathrm{D}}$ & $\begin{array}{l}6.34(1.53) \\
C, D\end{array}$ & $\begin{array}{l}8.23(2.93) \\
B, D\end{array}$ & $\begin{array}{l}13.91 \\
(4.44) *\end{array}$ & 39.75 & $3 / 168$ & $<0.001$ \\
\hline Emotional abuse & $\begin{array}{l}7.43(3.50) \\
C, D\end{array}$ & $\begin{array}{l}7.31(2.77) \\
C, D\end{array}$ & $\begin{array}{l}12.11 \\
(3.59) *\end{array}$ & $\begin{array}{l}17.40 \\
(5.27) *\end{array}$ & 62.60 & $3 / 168$ & $<0.001$ \\
\hline $\begin{array}{l}\text { Emotional } \\
\text { neglect }\end{array}$ & $\begin{array}{l}8.88(4.62) \\
C, D\end{array}$ & $\begin{array}{l}7.54(2.45) \\
\text { C,D }\end{array}$ & $\begin{array}{l}12.54 \\
(5.05)^{*}\end{array}$ & $\begin{array}{l}17.83 \\
(4.74) *\end{array}$ & 41.85 & $3 / 168$ & $<0.001$ \\
\hline Physical neglect & $\begin{array}{l}6.94(2.66) \\
C, D\end{array}$ & $\begin{array}{l}6.66 \text { (1.89) } \\
\text { C,D }\end{array}$ & $\begin{array}{l}8.20(3.58) \\
*\end{array}$ & $\begin{array}{l}11.97 \\
(3.90) *\end{array}$ & 24.95 & $3 / 168$ & $<0.001$ \\
\hline
\end{tabular}

ELT: early Lifetime Trauma

HOC: higher order construct

PON1: paraoxonase 1

\#: number of ...

HR-QoL:Health_Related Quality of Life

Table 3 shows the socio-demographic and clinical data of the participants in the staging groups. There were no significant differences in age, marital status, duration of illness, metabolic syndrome and use of lithium and antipsychotics among the groups. All the other variables showed significant differences with a lowered income in stages 2 and 3 and higher levels of HAM-D, HAM-A, YMRS and CGI in stages 2 and 3. Current suicidal ideation was significantly higher in stage 3 compared with all other subjects, while stages 1 and 2 also showed higher levels than controls. BMI was significantly higher in stage 3 compared with stage 1 and controls. Significantly more subjects in stage 3 used mood stabilizers than subjects in stage 1 . The prevalence of BP1 disorder was significantly higher in stages 2 and 3 than in stage 3.

6. Computation of a clinically useful staging algorithm

To compute an algorithm that may be used in clinical practice, we carried out a multiple regression analysis with the final ELT staging index as the dependent variable and its indicator variables or total ELT, and HR-QoL, Sheehan and CGI scores as explanatory variables. We found that $95.6 \%$ of the variance in the final ELT staging index could be explained by the regression on 
number of depressive and (hypo)maniac episodes and suicide attempts, and total ELT and CGI scores $\left(X^{2}=684.50, d f=5 / 159, p<0.001\right)$. Table 4 shows the results of the bootstrapped regression coefficients (1000 bootstraps). As such, the B values can be used to compute the unstandardized predicted values, which are an adequate index of the final ELT staging index. The latter is significantly associated with the BMI-MetS LV ( $\mathrm{r}=0.215, \mathrm{p}=0.006, \mathrm{n}=165)$, CMPAase activity $(\mathrm{r}=-0.261, \mathrm{p}=0.002, \mathrm{n}=144)$, the nitro-oxidative stress index $\mathrm{zSOD}+\mathrm{LOOH}+\mathrm{NOx}+\mathrm{AOPP}$ $(\mathrm{r}=0.318, \mathrm{p}<0.001, \mathrm{n}=134)$, cognitive LV $(\mathrm{r}=0.332, \mathrm{p}<0.001)$, VFT $(\mathrm{r}=-0.385, \mathrm{p}<0.001, \mathrm{n}=80)$, TMT_A $(\mathrm{r}=0.382, \mathrm{p}<0.001, \mathrm{n}=81)$ and TMT_B $(\mathrm{r}=0.298, \mathrm{p}=0.007, \mathrm{n}=80)$.

Table 4. Results of bootstrapped multiple regression analysis with the Final-ELT-staging index as outcome variable

\begin{tabular}{|c|c|c|c|c|c|c|c|}
\hline & & \multirow[b]{3}{*}{ B } & \multicolumn{5}{|c|}{ Bootstrap * } \\
\hline & & & & Std. & & 95\% Con & nce Interval \\
\hline \multicolumn{2}{|c|}{ Model } & & Bias & Error & Sig. (2-tailed) & Lower & Upper \\
\hline \multirow[t]{6}{*}{1} & (Constant) & -2.112 & -.018 & .054 & .001 & -2.234 & -2.030 \\
\hline & \#depressions & .074 & -.001 & .007 & .001 & .061 & .088 \\
\hline & $\begin{array}{l}\text { \#(hypo)manic } \\
\text { episodes }\end{array}$ & .013 & $\begin{array}{l}-8.655 \mathrm{E}- \\
5\end{array}$ & .004 & .003 & .001 & .020 \\
\hline & \#Suicide attempts & .063 & -.001 & .012 & .001 & .041 & .087 \\
\hline & Total ELT score & .034 & .000 & .001 & .001 & .031 & .037 \\
\hline & CGI & .085 & .002 & .013 & .001 & .060 & .112 \\
\hline
\end{tabular}

* Bootstrap results are based on 1000 bootstrap samples

\#: number of

ELT: Early Lifetime Trauma

CGI: Clinical Global Impression

\section{Construction of a biological-staging index.}

Finally, we have also examined whether the biomarkers could be reliably combined with the ELT-recurrence-outcome data. Table 1 shows the construct reliability of a fifth LV (named PON1-staging LV) with CMPAase activity (loadings=0.595), PON1 activity (0.524), number of depressive episodes (0.793), total number of episodes (0.753), HR-QoL (0.781) and Sheehan total score (0.698) as indicator variables. This LV showed good construct reliability with an AVE of $>$ 0.50 and adequate composite reliability, Cronbach's $\alpha$ and Rho_A values. This PON1-staging index was significantly associated with the recurrence index $(\mathrm{r}=0.731, \mathrm{p}<0.001, \mathrm{n}=172)$; staging index $(\mathrm{r}=0.725, \mathrm{p}<0.001, \mathrm{n}=172)$; ELT-staging HOC $(\mathrm{r}=0.793, \mathrm{p}<0.001, \mathrm{n}=172)$ and final ELT staging index $(0.794, \mathrm{p}<0.001, \mathrm{n}=172)$, ELT LV $(\mathrm{r}=0.507, \mathrm{p}<0.001, \mathrm{n}=172)$, the nitro-oxidative index $(\mathrm{r}=0.258, \mathrm{p}=0.001, \mathrm{n}=172)$, VFT $(\mathrm{r}=-0.374, \mathrm{p}<0.001, \mathrm{n}=83)$, and TMT_A $(\mathrm{r}=0.416, \mathrm{p}<0.001$, $\mathrm{n}=84)$, but not CRP $(\mathrm{r}=0.061, \mathrm{p}=0.440, \mathrm{n}=160)$. No latent constructs could be extracted from the indicators of the ELT-relapse LV and other biomarkers. 
Figure 5 shows the association between the 5 indices and the clinical diagnoses into MDD and BD type 1 and type 2. There were significant differences in the 5 staging indices between the groups $(\mathrm{F}=11.65, \mathrm{df}=15 / 453, \mathrm{p}<0.001$, partial eta squared $=0.259)$. The staging indices were significantly different between controls, major depression and bipolar disorder (no significant differences between type 1 and type 2).

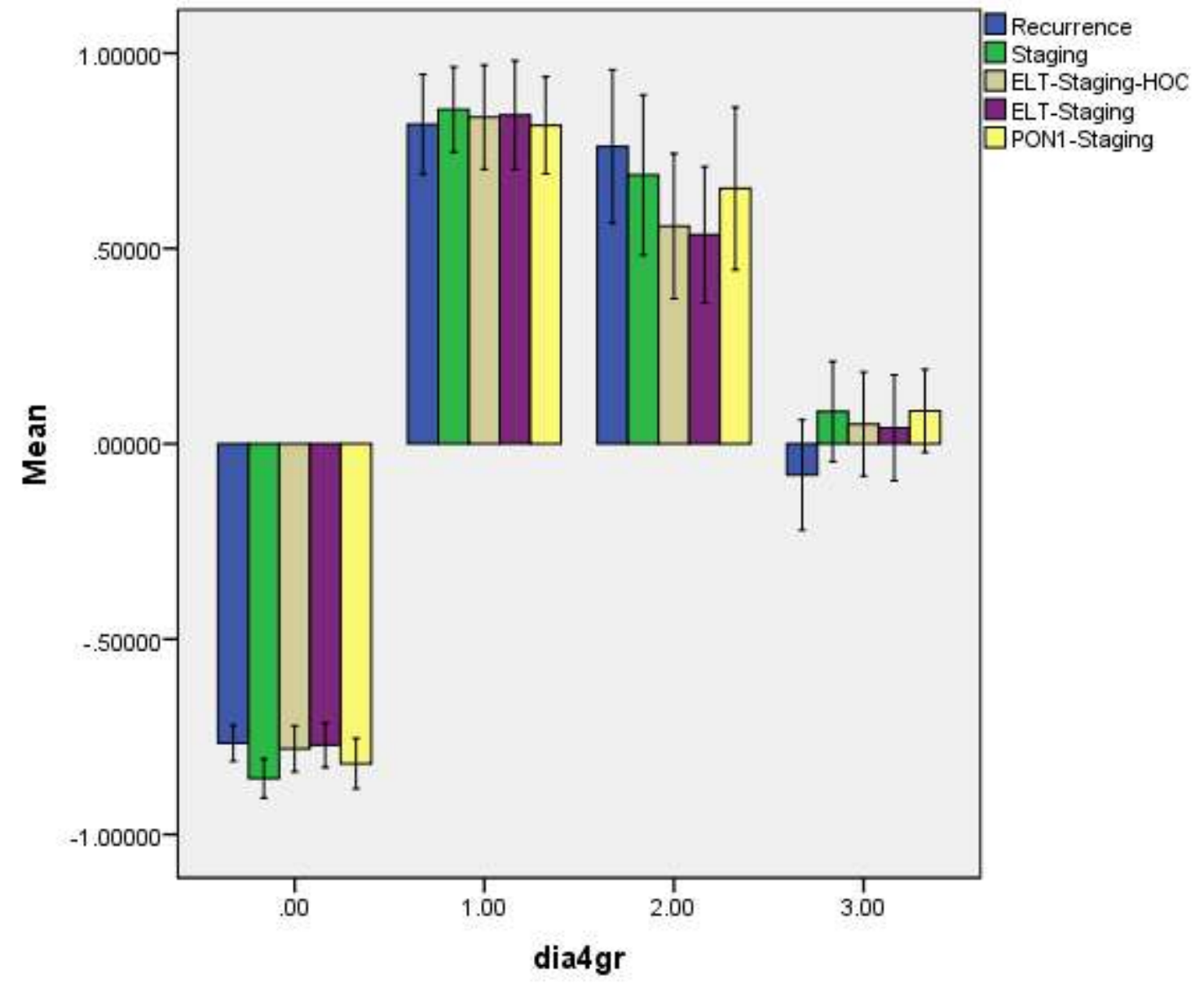

Error bars: $+/-1 \mathrm{SE}$

Figure 5. This figure shows the 5 new staging indices (mean values with $\mathrm{SE}$ of the $\mathrm{z}$ tansformations) that were computed in the current study in normal controls (00), patients with bipolar type 1 (1.00) and type 2 (2.00) and major depression (3.00).

Shown are the recurrence index (recurrence), Staging index (Staging), ELT-staging HOC (ELTStaging), Final ELT-staging index (ELT-staging) and PON1-staging index (PON1-staging).

\section{Discussion}

The main finding of this study was that, based on real data and consistent PLS bootstrapping (2000 bootstraps), we were able to construct staging indices, which showed excellent construct validity as indicated by adequate Cronbach's $\alpha$, composite reliability and AVE values. As such, our staging indices reflect relevant dimensions of affective phenomenology that are useful in clinical practice to assess severity of staging in both major depression and bipolar 
disorder. A first reliable staging index comprised relapse data as defined by the number of depressive and (hypo)manic episodes as well as lifetime suicide attempts. This relapse-staging index was significantly associated with female sex, effects of multiple ELTs and outcome variables including greater disabilities, lowered HR-QoL and impaired neurocognition, as well as socioeconomic data, use of psychotropic medications, current suicidal ideation, severity of illness, BMI and reduced antioxidant defenses, thus indicating excellent concurrent validity. Moreover, this relapse-staging index could be combined with ELTs, increased disabilities and lowered healthrelated quality of life (HR-QoL) as well as impairments in verbal fluency into an ELT-staging latent construct. A mathematical algorithm based on the latter may be used in clinical practice to score staging severity and to classify patients into three progressive stages of illness. Table 5 summarizes the clinical characteristics of these three stages. An early stage includes patients with few reoccurring episodes, increased lifetime and current suicidal ideation, and lowered verbal fluency, but no significant disabilities or changes in HR-QoL. The transition of stage 1 to stage 2 (the relapse-regression stage) is largely related to increased recurrent episodes and is characterized by increased disabilities, lower HR-QoL and lower socioeconomical status and cognitive processing speed. Stage 3 shows the same characteristics as stage 2 but, in addition, more ELTs in childhood, a higher recurrence of depressive, but not (hypo)manic, episodes, a trend towards executive dysfunctions, and highly increased suicidal behaviors, which is the hallmark of this suicidal-regression stage.

Table 5. Characteristics of the three stages of affective disoders as delineated in the present study

\begin{tabular}{|l|l|l|l|}
\hline Stages & $\begin{array}{l}\text { Stage 1: Early } \\
\text { stage }\end{array}$ & $\begin{array}{l}\text { Stage 2: } \\
\text { Relapse- } \\
\text { regression }\end{array}$ & $\begin{array}{l}\text { Stage 3: } \\
\text { Suicidal- } \\
\text { regression }\end{array}$ \\
\hline Early lifetime trauma & - & $\uparrow$ & $\uparrow \uparrow$ \\
\hline \# depressive episodes & $\uparrow$ & $\uparrow \uparrow$ & $\uparrow \uparrow \uparrow$ \\
\hline \# hypomanic episodes & $\uparrow$ & $\uparrow \uparrow$ & $\uparrow \uparrow$ \\
\hline \# suicidal attempts & $\uparrow$ & $\uparrow$ & $\uparrow \uparrow \uparrow$ \\
\hline Lifetime history suicidal idation & $\uparrow$ & $\uparrow$ & $\uparrow \uparrow$ \\
\hline Current suicidal ideation & $\uparrow$ & $\uparrow$ & $\uparrow \uparrow \uparrow$ \\
\hline Income & $\downarrow$ & $\downarrow \downarrow$ & $\downarrow \downarrow \downarrow$ \\
\hline Disabilities & $\uparrow$ & $\uparrow \uparrow$ & $\uparrow \uparrow$ \\
\hline Health-Related Quality of Life & $\downarrow$ & $\downarrow \downarrow$ & $\downarrow \downarrow$ \\
\hline Verbal fluency & $\downarrow$ & $\downarrow$ & $\downarrow$ \\
\hline Cognitive processing speed & $\downarrow$ & $\downarrow \downarrow$ & $\downarrow \downarrow$ \\
\hline Executive functioning & - & - & $\downarrow$ \\
\hline
\end{tabular}

Our staging models show significant differences from previous models proposed by Berk et al. [2], Kapczinski et al. [10] and Ferensztajn et al. [11]. For example, these models did not take into account the existence of a suicidal-regression phase (our stage 3 ) and did not consider ELT to be part of the model criteria. Nevertheless, our model and that of Kapczinski et al. [10] show some 
similar criteria including the use of relapses of episodes, interepisodic functioning and cognitive impairments. For example, there is a strong similarity between our stage 2/3 and Kapczinsky's stage 3, which use functional impairments as a key criterion. Major differences are that our model is based on statistical results of supervised machine learning (PLS path analysis) applied on real data from affective disorder patients, while previous models were based on common knowledge. Moreover, it should be noted that our ELT-staging model represents a key dimension of affective phenomenology, which is shared by both major depression and bipolar disorder and encompasse ELTs, the relapsing-remitting course, suicidal behaviors, progressive deterioration with functional deficits, cognitive impairments and disabilities. As such, this stage-defined index captures the trajectory of affective phenomenology from childhood to later retrogression stages.

The role of ELT in the development of affective disorders is now well established. Childhood traumatic events and especially their accumulation in childhood increase risk for developing both depression and bipolar disorder later in life [57-71]. Relapses of episodes (and by inference the relapse-remitting course), including recurrent suicidal behaviors, constitute the key component of all our staging indices. The number of depressive episodes increases from stage 1 $\rightarrow$ stage $2 \rightarrow$ stage 3 and the number of (hypo)manic episodes from stage 1 to stage $2 / 3$. Furthermore, a highly increased number of suicidal attempts is the hallmark of stage 3 . It is well known that both depression and bipolar disorder are highly recurrent disorders with an increased risk for suicidal attempts and behaviors [72-75]. In the present study, we found that the staging indices significantly increased from controls $\rightarrow$ major depression $\rightarrow$ bipolar disorder, while there were no significant differences between type 1 and type 2 bipolar disorder. Previously, it was shown that bipolar 1 individuals had a higher number of lifetime depressive episodes than bipolar 2 and major depressed patients [76,77] and that bipolar 1 and 2 patients had a higher number of lifetime depressive episodes compared with major depressed patients [31].

The current study showed that functional deficits, including increased disabilities, decreased quality of life and a decreased socioeconomical status, are hallmarks of the transition from stage 1 to stage 2/3. There is now evidence that major depression and bipolar disorder are among the leading sources of disability among younger adults worldwide [78,79], whereby a significant part of bipolar patients show impairments in their employment status and interepisode dysfunctions [80]. Both disorders are not only accompanied by increased functional disabilities but also by lowered HR-QoL [80-83].

Our findings showed that the components of the ELT-staging index share a large part of their variance, indicating that the indicators of this latent vector should be functionally associated. It is known that ELTs may cause more recurring episodes [65,84,85], and increased risk for subsequent suicidal behaviors $[86,87]$. The latter findings may also explain why ELTs are more prominent in stage 2 and especially in stage 3, which is characterized by increased ELT and suicidal behaviors. In this regard, it should be noted that the effects of female sex on the staging indices are mediated by higher ELT scores in females, suggesting that females with ELT are at increased risk to experience increased staging severity compared with their male counterparts [7]. Moreover, it is known that multiple ELTs are associated with increased severity of illness [61,69,71,88,89], decreased HR-QoL and increased disabilities in later life [90-93], delays in neurocognitive development [94,95] and higher BMI and obesity [96,97].

In the current study, we found that the cumulative effects of multiple ELTs, which appear to drive most outcome variables, are in fact mediated by the recurrence-staging index. Such findings may be explained by the knowledge that recurrent episodes and especially reoccurring suicidal attempts and suicidal ideation may affect work productivity and functions, thereby 
contributing to lower socio-economic status [33,98-100]. Moreover, ELTs and recurrent patterns and suicidal behaviors may affect the severity of illness, which in turn is accompanied by decreased HR-QoL [33,101].

The second major finding of this study was that lowered lipid-associated antioxidant defenses could be reliably combined with relapsing episodes, disabilities and HR-QoL into a PON1-staging index, which showed adequate composite reliability and that the final ELT-staging index was significantly associated with increasing nitro-oxidative stress. These findings suggest that lower antioxidant defenses and increased nitro-oxidative stress are important factors underpinning the pathophysiology of the ELT-staging process. Previous literature has shown that most, if not all, components of the ELT-staging index are associated with nitro-oxidative stress, lowered antioxidant defenses and related neuro-immune pathways.

Recently, we reported that, in affective disorders, physical neglect is associated with nitrooxidative biomarkers reflecting increased production of ROS/RNS, nitro-oxidative stress and lipid and protein oxidation [102]. Importantly, interactions between IL-6 and CRP single nucleotide polymorphisms and ELT increase risk towards major depression [103]. There is now evidence that, in humans, psychosocial stressors may cause nitro-oxidative stress and decreased antioxidant defenses [review: 102]. Animal models, including those that model chronic mild stress, chronic social isolation, swimming and restraint stress, are characterized by increased lipid and protein oxidation and lowered antioxidant levels in the brain [review: 102]. The second component of the ELT-staging index, namely, recurrence of episodes and suicidal behavior, was also significantly associated with lowered antioxidant defenses and neuro-oxidative and neuro-immune biomarkers $[26,30,31,104]$. For example, Sowa-Kucma et al. [31] reported that the number of affective episodes was significantly associated with increased lipid peroxidation and signs of cell-mediated immune activation, while Moreira et al. [26] established that lowered lipid-associated antioxidant defenses are associated with increased numbers of depressive and (hypo)manic phases. Celik et al. [104] and Maes et al. [30] found positive associations between the number of lifetime depressive episodes and immune biomarkers including neopterin and cytokines. These neuro-immune data are relevant to our current results because, in affective disorders, neuro-immune and neurooxidative pathways are interrelated phenomena [105]. Interestingly, lowered PON1 activity is already present in patients with a first episode of psychosis of whom a considerable percentage will develop bipolar disorder [106], while lowered PON1-related antioxidant defenses are significantly associated with activated neuro-oxidative and neuro-immune pathways in affective disorders [26].

In the current study, suicidal behaviors are a key component of the staging models and a hallmark of stage 3. Previously, it was shown that current suicidal ideation is associated with increased signs of lipid peroxidation and that a history of lifetime suicidal attempts is associated with increased lipid peroxidation and signs of immune activation [31]. Vargas et al. [107] reported that prior suicidal attempts are accompanied by increased lipid hydroperoxides and lower total radical trapping antioxidant parameters, suggesting that lipid peroxidation and lowered antioxidant defenses are biomarkers of suicidal attempts. Additionally, the outcome variables measured here were strongly related with lipid-associated antioxidant defenses, including income, CGI, HR-QoL and disabilities. Recently, we reported that lowered HR-QoL and its subdomains in affective disorders are associated with increased levels of malondialdehyde, advanced oxidation protein products and lowered CMPAase PON1 activity [33]. Finally, there is now some evidence that increased neuro-oxidative stress and neuro-immune pathways may affect neurocognitive functions in affective disorders [108]. It is interesting to note that the significant effects of the recurrence- 
staging LV on hsCRP and insulin resistance were in fact mediated by the effects of recurrencestaging on BMI. These findings may explain why both hsCRP and insulin resistance are biomarkers of affective disorders [32,109], while controlling for BMI shows that both biomarkers do not always discriminate patients with depression or bipolar disorder from controls $[32,70]$. The other two biomarkers examined here, including uric acid and basal TSH levels, were not significantly associated with the staging indices.

The results of our study should be interpreted with respect to its limitations. First, we did not include patients with chronic depression or refractory depression (TRD), although they were important indicators in previous staging models $[9,11]$. It remains to be elucidated whether TRD belongs to the same ELT-staging index or is a separate entity that should be treated differently. Second, we excluded patients with comorbid conditions (apart from DSM-5 anxiety disorders) including psychosis and medical disorders, although in clinical practice these comorbidities are very common and probably deteriorate staging. For example, cardiovascular disorders are common comorbidities with affective disorders and are accompanied by lowered PON1 activities and increased neuro-oxidative stress [26]. Third, our study was a cross-sectional study and, therefore, no causal inferences can be made. Fourth, it would have been more interesting if we had measured a panel of cytokines to compute the inflammatory/anti-inflammatory indices [110]. Finally, although the model herein proposed was validated using the bootstrap method, the model deserves validation in independent study samples.

Figure 6 summarizes our findings. We constructed an ELT-staging index that reflects a key dimension of affective phenomenology, shared by both major depression and bipolar disorder and encompassing ELTs, reoccurring episodes and suicidal behaviors, and a progressive functional retrogression with increased disabilities, impairments in verbal fluency, cognitive processing speed and executive functions, and lower HR-QoL. Female sex has a significant impact on the staging indices and this effect is mediated by increased ELT scores in females. The ELT-staging index is significantly associated with increased nitro-oxidative stress, while lowered serum paraoxonase 1 activities combines with recurrent episodes, disabilities and HR-QoL into a relevant biological dimension. Moreover, based on the ELT-staging index, which reflects severity of staging, we defined three stages: 1) an early stage; 2) a relapse-retrogression stage; and 3) a suicidal-retrogression stage. This staging model may help to tailor interventions in the early stage to prevent the transition from stage 1 to stages $2 / 3$. Our results suggest that treatments that target lowered lipid-associated antioxidant defenses may be useful to this end. 


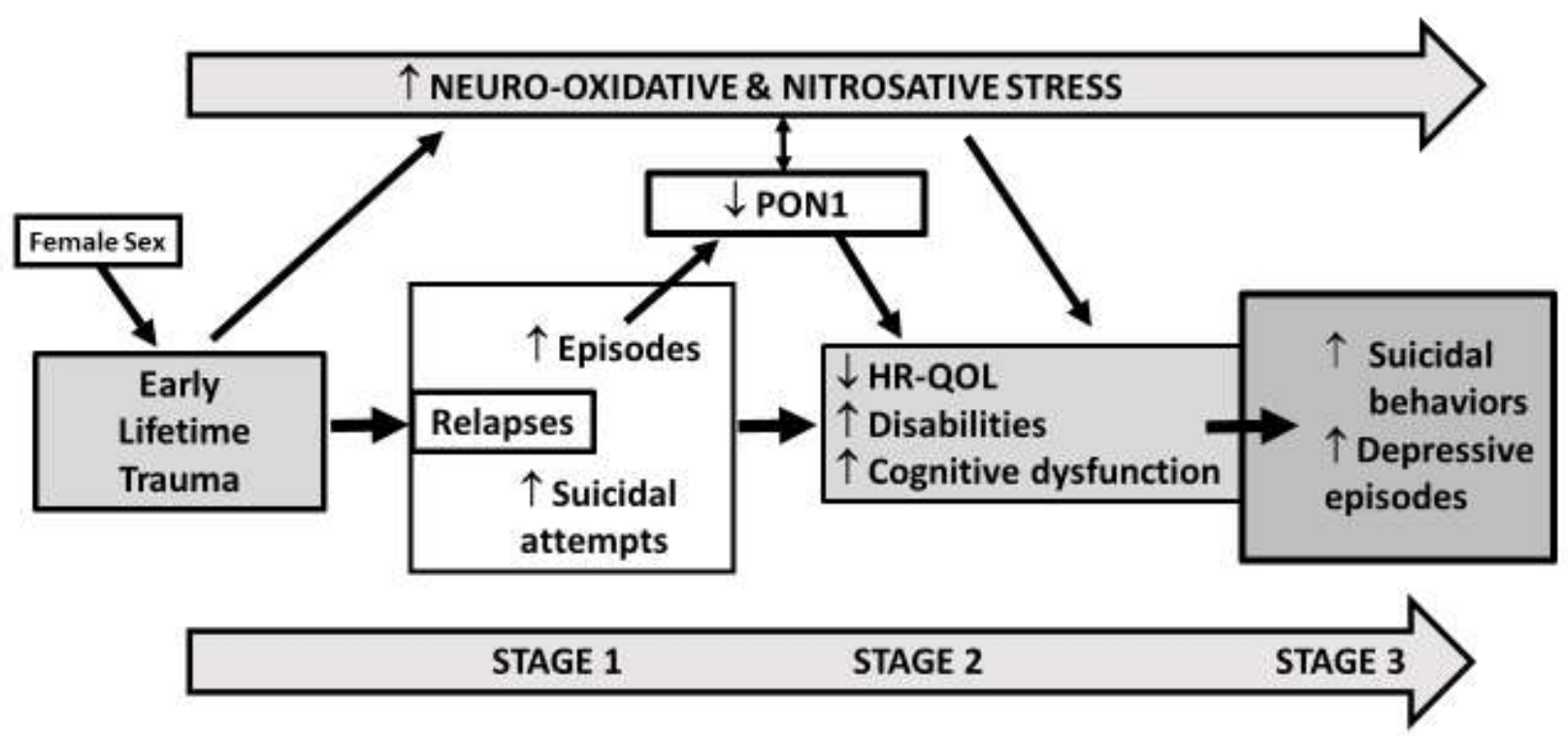

Figure 6. New staging model of affective disoders showing a key dimension of affective phenomenology, shared by both major depression and bipolar disorder, and which encompasses early lifetime traumata (ELT), reoccurring episodes and suicidal behaviors, and a progressive functional retrogression with increased disabilities, impairments in cognitive processes and lower HR-QoL. Female sex had a significant impact on this staging index which was mediated by increased ELT scores in females. Lowered serum paraoxonase 1 activities (PON1) may be combined with recurrent episodes, disabilities and HR-QoL into a latent construct with adequate composite reliability, while the staging index is also significantly associated with increased nitrooxidative stress. Three stages of progressing severity were defined: 1) an early stage; 2) a relapseretrogression stage; and 3) a suicidal-retrogression stage.

Funding: This study was supported by Health Sciences Postgraduate Program at Londrina State University, Parana, Brazil (UEL), and Ministry for Science and Technology of Brazil (CNPq). CNPq number 470344/2013-0 and CNPq number 465928/2014-5. MM is supported by a CNPq PVE fellowship and the Health Sciences Graduate Program fellowship, State University of Londrina.

Acknowledgements: The authors wish to thank the Centre of Approach and Treatment for Smokers, Psychiatric Unit at UEL, Clinical Laboratory of the University Hospital and Laboratory of Research and Graduate College Hospital (LPG), Brazil.

Authorships: All authors contributed to the writing up of the paper. The work was designed by SOVN, MM, DSB, JBM and HOV. Data were collected by SOVN, HOV, AC and JBM. Laboratory analyses were conducted by KLB, APM and DSB. Statistics were performed by MM. AFC revised the manuscript and provided relevant intellectual content. All authors revised and approved the final draft. 


\section{References}

1. Berk M, Brnabic A, Dodd S, Kelin K, Tohen M, Malhi GS, Berk L, Conus P, McGorry PD (2011) Does stage of illness impact treatment response in bipolar disorder? Empirical treatment data and their implication for the staging model and early intervention. Bipolar Disord 13(1):8798.

2. Scott J, Leboyer M, Hickie I, Berk M, Kapczinski F, Frank E, Kupfer D, McGorry P (2013) Clinical staging in psychiatry: a cross-cutting model of diagnosis with heuristic and practical value. Br J Psychiatry 202(4):243-245.

3. Moylan S, Maes M, Wray NR, Berk M (2013) The neuroprogressive nature of major depressive disorder: pathways to disease evolution and resistance, and therapeutic implications. Mol Psychiatry 18(5):595-606.

4. Muneer A (2016) Staging Models in Bipolar Disorder: A Systematic Review of the Literature. Clin Psychopharmacol Neurosci 31(2):117-30.

5. Mwangi B, Wu MJ, Cao B, Passos IC, Lavagnino L, Keser Z, Zunta-Soares GB, Hasan KM, Kapczinski F, Soares JC (2016) Individualized Prediction and Clinical Staging of Bipolar Disorders using Neuroanatomical Biomarkers. Biol Psychiatry Cogn Neurosci Neuroimaging 1(2):186-194.

6. Passos IC, Kapczinski F (2017) Should bipolar disorder treatment be modified depending on staging? Expert Rev Neurother 17(2):93-95.

7. Maes M, Congio A, Moraes JB, Bonifacio KL, Barbosa DS, Vargas HO, Morris G, Puri BK, Michelin AP, Nunes SOV (2018) Early Life Trauma Predicts Affective Phenomenology and the Effects are Partly Mediated by Staging Coupled with Lowered Lipid-Associated Antioxidant Defences. Biomol Concepts 9(1):115-130.

8. Cosci F, Fava GA (2013) Staging of mental disorders: systematic review. Psychother Psychosom 82(1):20-34.

9. Berk M, Berk L, Dodd S, Cotton S, Macneil C, Daglas R, Conus P, Bechdolf A, Moylan S, Malhi GS (2014) Stage managing bipolar disorder. Bipolar Disord 16(5):471-417.

10. Kapczinski F, Dias VV, Kauer-Sant'Anna M, Brietzke E, Vázquez GH, Vieta E, Berk M (2009) The potential use of biomarkers as an adjunctive tool for staging bipolar disorder. Prog Neuropsychopharmacol Biol Psychiatry 33(8):1366-1371.

11. Ferensztajn E, Remlinger-Molenda A, Rybakowski J (2014) Staging of unipolar affective illness. Psychiatr Pol 48(6):1127-1141.

12. Maes M, Landucci Bonifacio K, Morelli NR, Vargas HO, Barbosa DS, Carvalho AF, Nunes SOV (2018) Major Differences in Neurooxidative and Neuronitrosative Stress Pathways Between 
Major Depressive Disorder and Types I and II Bipolar Disorder. Mol Neurobiol April 21. doi: 10.1007/s12035-018-1051-7.

13. Maes M, Carvalho AF (2018) The Compensatory Immune-Regulatory Reflex System (CIRS) in Depression and Bipolar Disorder. Mol Neurobiol 55(12):8885-8903.

14. Maes M (1995) Evidence for an immune response in major depression: a review and hypothesis. Prog Neuropsychopharmacol Biol Psychiatry 19(1):11-38.

15. Leonard B, Maes M (2012) Mechanistic explanations how cell-mediated immune activation, inflammation and oxidative and nitrosative stress pathways and their sequels and concomitants play a role in the pathophysiology of unipolar depression. Neurosci Biobehav Rev 36(2):764-785.

16. Maes M, Galecki P, Chang YS, Berk M (2011) A review on the oxidative and nitrosative stress (O\&NS) pathways in major depression and their possible contribution to the (neuro)degenerative processes in that illness. Prog Neuropsychopharmacol Biol Psychiatry 35(3):676-692.

17. Peet M, Murphy B, Shay J, Horrobin D (1998) Depletion of omega-3 fatty acid levels in red blood cell membranes of depressive patients. Biol Psychiatry 43(5):315-319.

18. Maes M, Smith R, Christophe A, Cosyns P, Desnyder R, Meltzer H (1996) Fatty acid composition in major depression: decreased omega 3 fractions in cholesteryl esters and increased C20: 4 omega 6/C20:5 omega 3 ratio in cholesteryl esters and phospholipids. J Affect Disord 38(1):35-46.

19. Maes M, Delanghe J, Meltzer HY, Scharpé S, D'Hondt P, Cosyns P (1994) Lower degree of esterification of serum cholesterol in depression: relevance for depression and suicide research. Acta Psychiatr Scand 90(4):252-258.

20. Maes M, Smith R, Christophe A, Vandoolaeghe E, Van Gastel A, Neels H, Demedts P, Wauters A, Meltzer HY (1997) Lower serum high-density lipoprotein cholesterol (HDL-C) in major depression and in depressed men with serious suicidal attempts: relationship with immuneinflammatory markers. Acta Psychiatr Scand 95(3):212-221.

21. Maes M, De Vos N, Pioli R, Demedts P, Wauters A, Neels H, Christophe A (2000) Lower serum vitamin $\mathrm{E}$ concentrations in major depression. Another marker of lowered antioxidant defenses in that illness. J Affect Disord 58(3):241-246.

22. Maes M, Mihaylova I, Kubera M, Uytterhoeven M, Vrydags N, Bosmans E (2009) Lower plasma Coenzyme Q10 in depression: a marker for treatment resistance and chronic fatigue in depression and a risk factor to cardiovascular disorder in that illness. Neuro Endocrinol Lett 30(4):462-469.

23. Sobczak S, Honig A, Christophe A, Maes M, Helsdingen RW, De Vriese SA, Riedel WJ (2004) Lower high-density lipoprotein cholesterol and increased omega- 6 polyunsaturated fatty acids in first-degree relatives of bipolar patients. Psychol Med 34(1):103-112. 
24. Tsuboi H, Tatsumi A, Yamamoto K, Kobayashi F, Shimoi K, Kinae N (2006) Possible connections among job stress, depressive symptoms, lipid modulation and antioxidants. J Affect Disord 91(1):63-70.

25. Nunes SO, Piccoli de Melo LG, Pizzo de Castro MR, Barbosa DS, Vargas HO, Berk M, Maes M (2015) Atherogenic index of plasma and atherogenic coefficient are increased in major depression and bipolar disorder, especially when comorbid with tobacco use disorder. J Affect Disord 172:55-62.

26. Moreira EG, Correia DG, Bonifácio KL, Moraes JB, Cavicchioli FL, Nunes CS, Nunes SOV, Vargas HO, Barbosa DS, Maes M (2017) Lowered PON1 activities are strongly associated with depression and bipolar disorder, recurrence of (hypo)mania and depression, increased disability and lowered quality of life. World J Biol Psychiatry 30:1-13.

27. Bilici M, Efe H, Köroğlu MA, Uydu HA, Bekaroğlu M, Değer O (2001) Antioxidative enzyme activities and lipid peroxidation in major depression: alterations by antidepressant treatments. J Affect Disord 64(1):43-51.

28. Maes M, Mihaylova I, Kubera M, Uytterhoeven M, Vrydags N, Bosmans E (2010) Increased plasma peroxides and serum oxidized low density lipoprotein antibodies in major depression: markers that further explain the higher incidence of neurodegeneration and coronary artery disease. J Affect Disord 125(1-3):287-294.

29. Morris G, Walder K, Puri BK, Berk M, Maes M (2016) The Deleterious Effects of Oxidative and Nitrosative Stress on Palmitoylation, Membrane Lipid Rafts and Lipid-Based Cellular Signalling: New Drug Targets in Neuroimmune Disorders. Mol Neurobiol 53(7):4638-4658.

30. Maes M, Mihaylova I, Kubera M, Ringel K (2012) Activation of cell-mediated immunity in depression: association with inflammation, melancholia, clinical staging and the fatigue and somatic symptom cluster of depression. Prog Neuropsychopharmacol Biol Psychiatry 36(1):169175.

31. Sowa-Kućma M, Styczeń K, Siwek M, Misztak P, Nowak RJ, Dudek D, Rybakowski JK, Nowak G, Maes M (2018) Are there differences in lipid peroxidation and immune biomarkers between major depression and bipolar disorder: Effects of melancholia, atypical depression, severity of illness, episode number, suicidal ideation and prior suicide attempts. Prog Neuropsychopharmacol Biol Psychiatry 81:372-383.

32. de Melo LGP, Nunes SOV, Anderson G, Vargas HO, Barbosa DS, Galecki P, Carvalho AF, Maes M (2017) Shared metabolic and immune-inflammatory, oxidative and nitrosative stress pathways in the metabolic syndrome and mood disorders. Prog Neuropsychopharmacol Biol Psychiatry 78:34-50.

33. Nunes CS, Maes M, Roomruangwong C, Moraes JB, Bonifacio KL, Vargas HO, Barbosa DS, Anderson G, de Melo LGP, Drozdstoj S, Moreira E, Carvalho AF, Nunes SOV (2018) Lowered 
quality of life in mood disorders is associated with increased neuro-oxidative stress and basal thyroid-stimulating hormone levels and use of anticonvulsant mood stabilizers. J Eval Clin Pract 24(4):869-878.

34. Del-Ben CM, Vilela JAA, Crippa JAdS, Hallak JEC, Labate CM, et al. (2001) Confiabilidade da "Entrevista Clínica Estruturada para o DSM-IV - Versão Clínica" traduzida para o português. Revista Brasileira de Psiquiatria 23:156-159.

35. American Psychiatric Association (2000) Diagnostic and statistical manual of mental disorders (4th ed., Text Revision). Washington, DC: Author.

36. Hamilton M (1959) The assessment of anxiety states by rating. Br J Med Psychol 32, 50-55.

37. Hamilton M (1960) A rating scale for depression. J Neurol Neurosurg Psychiatry 23, 56-62.

38. Vilela JA, Crippa JA, Del-Ben CM, Loureiro SR (2005) Reliability and validity of a Portuguese version of the Young Mania Rating Scale. Braz J Med Biol Res 38(9):1429-1439.

39. Sheehan DV, Harnett-Sheehan K, Raj BA (1996) The measurement of disability. Int Clin Psychopharmacol 11 Suppl 3:89-95.

40. WHO (1993) Study protocol for the World Health Organization project to develop a Quality of Life assessment instrument (WHOQOL). Qual Life Res 2(2):153-159.

41. Skevington SM, Lotfy M, O'Connell KA; WHOQOL Group (2004) The World Health Organization's WHOQOL-BREF quality of life assessment: psychometric properties and results of the international field trial. A report from the WHOQOL group. Qual Life Res 13(2):299-310.

42. Fleck MP, Louzada S, Xavier M, et al (2000) Application of the Portuguese version of the abbreviated instrument of quality life WHOQOL-bref. Rev Saude Publica 34(2):178-183.

43. Guy W (1976) "Clinical Global Impressions". ECDEU Assessment Manual for Psychopharmacology-Revised. Rockville, MD: U.S. Department of Health, Education, and Welfare; Public Health Service, Alcohol; Drug Abuse, and Mental Health Administration; National Institute of Mental Health; Psychopharmacology Research Branch; Division of Extramural Research Programs. pp. 218-222.

44. Posner K, Brown GK, Stanley B, Brent DA, Yershova KV, Oquendo MA, Currier GW, Melvin GA, Greenhill L, Shen S, Mann JJ (2011) The Columbia-Suicide Severity Rating Scale: initial validity and internal consistency findings from three multisite studies with adolescents and adults. Am J Psychiatry 168(12):1266-1277.

45. Jensen A (1965) Scoring the Stroop test. Acta Psychologica 24:398-408

46. Reitan RM (1958) Validity of theTrail making Test as an indication of organic brain damage. Percept Motor Skills 8:271-276. 
47. Bernstein DP, Stein JA, Newcomb MD, Walker E, Pogge D, Ahluvalia T, Stokes J, Handelsman L, Medrano M, Desmond D, Zule W (2003) Development and validation of a brief screening version of the Childhood Trauma Questionnaire. Child Abuse Negl 27(2):169-190.

48. Grassi-Oliveira R, Stein LM, Pezzi JC (2006) Translation and content validation of the Childhood Trauma Questionnaire into Portuguese language. Rev Saude Publica 40:249-255.

49. Levy JC, Matthews DR, Hermans MP (1998) Correct homeostasis model assessment (HOMA) evaluation uses the computer program. Diabetes Care 21(12):2191-2192.

50. Marklund S, Marklund G (1974) Involvement of the superoxide dismutase anion radical in the autoxidation of pyrogallol and a convenient assay for superoxide dismutase. Eur J Biochem 47:469-471.

51. Gonzalez Flecha B, Llesuy S, Boveris A (1991) Hydroperoxide-initiated chemiluminescence: an assay for oxidative stress in biopsies of heart, liver, and muscle. Free Radic Biol Med 10:93100.

52. Panis C, Herrera ACSA, Victorino VJ, Campos FC, Freitas LF, De Rossi T, Colado Simao AN, Cecchini AL, Cecchini R (2012) Oxidative stress and hematological profiles of advanced breast cancer patients subjected to paclitaxel or doxorubicin chemotherapy. Breast Cancer Res Treat 133:89-97.

53. Navarro-Gonzalvez JA, Garcia-Benayas C, Arenas J (1998) Semiautomated measurement of nitrate in biological fluids. Clin Chem 44:679-681.

54. Hanasand M, Omdal R, Norheim KB, Gransson LG, Brede C, Jonsson G (2012) Improved detection of advanced oxidation protein products in plasma. Clin Chim Acta 413:901-906.

55. Bastos AS, Loureiro AP, de Oliveira TF, Corbi SC, Caminaga RM, Junior CR, Orrico SR (2012) Quantitation of malondialdehyde in gingival crevicular fluid by a high-performance liquid chromatography-based method. Anal Biochem 423:141-146.

56. Ringle CM, Wende S, Becker J-M. SmartPLS 3. Bönningstedt: SmartPLS, 2015. Retrieved (29-11-2018) from http://www.smartpls.com

57. Marangoni C, Hernandez M, Faedda GL (2016) The role of environmental exposures as risk factors for bipolar disorder: A systematic review of longitudinal studies. J Affect Disord 193:16574.

58. Catone G, Marwaha S, Kuipers E, Lennox B, Freeman D, Bebbington P, Broome M (2015) Bullying victimisation and risk of psychotic phenomena: analyses of British national survey data. Lancet Psychiatry 2:618-624. 
59. Fisher HL, Jones PB, Fearon P, Craig TK, Dazzan P, Morgan K, Hutchinson G, Doody GA, McGuffin P, Leff J, Murray RM, Morgan C (2010) The varying impact of type, timing and frequency of exposure to childhood adversity on its association with adult psychotic disorder. Psychol Med 40:1967-1978.

60. Takizawa R, Maughan B, Arseneault L (2014) Adult health outcomes of childhood bullying victimization: evidence from a five-decade longitudinal British birth cohort. Am J Psychiatry 171:777-784.

61. Alvarez MJ, Roura P, Oses A, Foguet Q, Sola J, Arrufat FX (2011) Prevalence and clinical impact of childhood trauma in patients with severe mental disorders. J Nerv Ment Dis 199:156161.

62. Bergink V, Larsen JT, Hillegers MH, Dahl SK, Stevens H, Mortensen PB, Petersen L, MunkOlsen T (2016) Childhood adverse life events and parental psychopathology as risk factors for bipolar disorder. Transl Psychiatry 6:e929.

63. Heim C, Shugart M, Craighead WE, Nemeroff CB (2010) Neurobiological and psychiatric consequences of child abuse and neglect. Dev Psychobiol 52:671-690.

64. Larsson S, Andreassen OA, Aas M, et al (2013) High prevalence of childhood trauma in patients with schizophrenia spectrum and affective disorder. Compr Psychiatry 54(2):123-127.

65. Etain B, Lajnef M, Henry C, Aubin V, Azorin JM, Bellivier F, Bougerol T, Courtet P, Gard S, Kahn JP, Passerieux C, Leboyer M; FACE-BD Clinical Coordinating Center (FondaMental Foundation); FACE-BD Data Coordinating Center (FondaMental Foundation); FACE-BD Clinical Sites and Principal Collaborators in France (2017) Childhood trauma, dimensions of psychopathology and the clinical expression of bipolar disorders: A pathway analysis. J Psychiatr Res 95:37-45.

66. Widom CS, DuMont K, Czaja SJ (2007) A prospective investigation of major depressive disorder and comorbidity in abused and neglected children grown up. Arch Gen Psychiatry 64(1):49-56.

67. Tanskanen A, Hintikka J, Honkalampi K, Haatainen K, Koivumaa-Honkanen H, Viinamäki H (2004) Impact of multiple traumatic experiences on the persistence of depressive symptoms--a population-based study. Nord J Psychiatry 58(6):459-464.

68. Negele A, Kaufhold J, Kallenbach L, Leuzinger-Bohleber M (2015) Childhood Trauma and Its Relation to Chronic Depression in Adulthood. Depress Res Treat 2015:650804.

69. Aas M, Henry C, Bellivier F, Lajnef M, Gard S, Kahn JP, Lagerberg TV, Aminoff SR, Bjella T, Leboyer M, Andreassen OA, Melle I, Etain B (2017) Affective lability mediates the association between childhood trauma and suicide attempts, mixed episodes and co-morbid anxiety disorders in bipolar disorders. Psychol Med 47(5):902-912. 
70. Moraes JB, Maes M, Barbosa DS, Ferrari TZ, Uehara MKS, Carvalho AF, Nunes SOV (2017) Elevated C-reactive Protein Levels in Women with Bipolar Disorder may be Explained by a History of Childhood Trauma, Especially Sexual Abuse, Body Mass Index and Age. CNS Neurol Disord Drug Targets 16(4):514-521.

71. Janiri D, Sani G, Danese E, Simonetti A, Ambrosi E, Angeletti G, Erbuto D, Caltagirone C, Girardi P, Spalletta G (2015) Childhood traumatic experiences of patients with bipolar disorder type I and type II. J Affect Disord 175:92-97.

72. American Psychiatric Association (2013) Bipolar Disorder. In Diagnostic and Statistical Manual of Mental Disorders (5th ed), 571-577.

73. Bolton JM, Gunnell D, Turecki G (2015) Suicide risk assessment and intervention in people with mental illness. BMJ 351:h4978.

74. Miret M, Ayuso-Mateos JL, Sanchez-Moreno J, Vieta E (2013) Depressive disorders and suicide: Epidemiology, risk factors, and burden. Neurosci Biobehav Rev 37(10 Pt 1):2372-2374.

75. Novick DM, Swartz HA, Frank E (2010) Suicide attempts in bipolar I and bipolar II disorder: a review and meta-analysis of the evidence. Bipolar Disord 12(1):1-9.

76. Moreno C, Hasin DS, Arango C, Oquendo MA, Vieta E, Liu S, Grant BF, Blanco C (2012) Depression in bipolar disorder versus major depressive disorder: results from the National Epidemiologic Survey on Alcohol and Related Conditions. Bipolar Disord 14(3):271-282.

77. Perlis RH, Brown E, Baker RW, Nierenberg AA (2006) Clinical features of bipolar depression versus major depressive disorder in large multicenter trials. Am J Psychiatry 163(2):225-231.

78. Murray CJ, Vos T, Lozano R, et al (2012) Disability-adjusted life years (DALYs) for 291 diseases and injuries in 21 regions, 1990-2010: a systematic analysis for the Global Burden of Disease Study 2010. Lancet 380(9859):2197-2223.

79. Lopez AD, Mathers CD, Ezzati M, et al (2006) Global and regional burden of disease and risk factors, 2001: systematic analysis of population health data. Lancet 367(9524):1747-1757.

80. Birnbaum HG, Kessler RC, Kelley D, Ben-Hamadi R, Joish VN, Greenberg PE (2010) Employer burden of mild, moderate, and severe major depressive disorder: mental health services utilization and costs, and work performance. Depress Anxiety 27:78-89.

81. Dean BB, Gerner D, Gerner RH (2004) A systematic review evaluating health-related quality of life, work impairment, and healthcare costs and utilization in bipolar disorder. Curr Med Res Opin 20:139-154.

82. Depp CA, Mausbach BT, Harmell AL, Savla GN, Bowie CR, Harvey PD, Patterson TL (2012) Meta-analysis of the association between cognitive abilities and everyday functioning in bipolar disorder. Bipolar Disord 14:217-226. 
83. GBD 2015 DALYs and HALE Collaborators (2016) Global, regional, and national disabilityadjusted life-years (DALYs) for 315 diseases and injuries and healthy life expectancy (HALE), 1990-2015: a systematic analysis for the Global Burden of Disease Study. Lancet 388:1603-1658.

84. Agnew-Blais J, Danese A (2016) Childhood maltreatment and unfavourable clinical outcomes in bipolar disorder: a systematic review and meta-analysis. Lancet Psychiatry 3(4):342-349.

85. Jansen K, Cardoso TA, Fries GR, Branco JC, Silva RA, Kauer-Sant'Anna M, Kapczinski F, Magalhaes PV (2016) Childhood trauma, family history, and their association with mood disorders in early adulthood. Acta Psychiatr Scand 134:281-286.

86. Hadland SE, Marshall BD, Kerr T, Qi J, Montaner JS, Wood E (2012) Suicide and history of childhood trauma among street youth. J Affect Disord 136:377-380.

87. Roy A, Janal M (2005) Family history of suicide, female sex, and childhood trauma: separate or interacting risk factors for attempts at suicide? Acta Psychiatr Scand 112:367-371.

88. Krug EG, Dahlberg LL, Mercy J, Zwi A, Lozano R (2002) Child abuse and neglect by parents and other caregivers. World Health Organization. World Report on Violence and Health, pp. 5986.

89. Schoedl AF, Costa MC, Mari JJ, Mello MF, Tyrka AR, Carpenter LL, Price LH (2010) The clinical correlates of reported childhood sexual abuse: an association between age at trauma onset and severity of depression and PTSD in adults. J Child Sex Abus 19:156-170.

90. Ventegodt S, Flensborg-Madsen T, Andersen NJ, Merrick J (2008) Which factors determine our quality of life, health and ability? Results from a Danish population sample and the Copenhagen perinatal cohort. J Coll Physicians Surg Pak 18(7):445-450.

91. Erten E, Funda Uney A, Saatçioğlu Ö, Özdemir A, Fıstıkçı N, Çakmak D (2014) Effects of childhood trauma and clinical features on determining quality of life in patients with bipolar I disorder. J Affect Disord 162:107-113.

92. Afifi TO, Enns MW, Cox BJ, de Graaf R, ten Have M, Sareen J (2007) Child abuse and healthrelated quality of life in adulthood. J Nerv Ment Dis 195:797-804.

93. Chahine EF (2014) Child Abuse and its Relation to Quality of Life of Male and Female Children. Procedia-Social and Behavioral Sciences 159:161-168.

94. Pechtel P, Pizzagalli DA (2011) Effects of early life stress on cognitive and affective function: an integrated review of human literature. Psychopharmacology (Berl) 214(1):55-70.

95. Kaplan GA, Turrell G, Lynch JW, Everson SA, Helkala EL, Salonen JT (2001) Childhood socioeconomic position and cognitive function in adulthood. Int J Epidemiol 30(2):256-263. 
96. Hepgul N, Pariante CM, Dipasquale S, DiForti M, Taylor H, Marques TR, Morgan C, Dazzan P, Murray RM, Mondelli V (2012) Childhood maltreatment is associated with increased body mass index and increased C-reactive protein levels in first-episode psychosis patients. Psychol Med 42(9):1893-1901.

97. Danese A, Tan M (2014) Childhood maltreatment and obesity: systematic review and metaanalysis. Mol Psychiatry 19(5):544-554.

98. Kim JH, Kwon JW (2012) The impact of health-related quality of life on suicidal ideation and suicide attempts among Korean older adults. J Gerontol Nurs 38(11):48-59.

99. Bowden CL (2005) Bipolar disorder and work loss. Am J Manag Care 11(3 Suppl):S91-94.

100. Michalak EE, Yatham LN, Lam RW (2005) Quality of life in bipolar disorder: a review of the literature. Health Qual Life Outcomes 3:72.

101. Woo JM, Jeon HJ, Noh E, Kim HJ, Lee SW, Lee KK, Kim SH, Hong JP (2014) Importance of remission and residual somatic symptoms in health-related quality of life among outpatients with major depressive disorder: a cross-sectional study. Health Qual Life Outcomes 12:188.

102. Moraes JB, Maes M, Roomruangwong C, Bonifacio KL, Barbosa DS, Vargas HO, Anderson G, Kubera M, Carvalho AF, Nunes SOV (2018) In major affective disorders, early life trauma predict increased nitro-oxidative stress, lipid peroxidation and protein oxidation and recurrence of major affective disorders, suicidal behaviors and a lowered quality of life. Metab Brain Dis 33(4):1081-1096.

103. Cohen-Woods S, Fisher HL, Ahmetspahic D, Douroudis K, Stacey D, Hosang GM, Korszun A, Owen M, Craddock N, Arolt V, Dannlowski U, Breen G, Craig IW, Farmer A, Baune BT, Lewis CM, Uher R, McGuffin P (2018) Interaction between childhood maltreatment on immunogenetic risk in depression: Discovery and replication in clinical case-control samples. Brain Behav Immun 67:203-210.

104. Celik C, Erdem M, Cayci T, Ozdemir B, Ozgur Akgul E, Kurt YG, Yaman H, Isintas M, Ozgen F, Ozsahin A (2010) The association between serum levels of neopterin and number of depressive episodes of major depression. Prog Neuropsychopharmacol Biol Psychiatry 34(2):372375.

105. Moylan S, Berk M, Dean OM, Samuni Y, Williams LJ, O'Neil A, Hayley AC, Pasco JA, Anderson G, Jacka FN, Maes M (2014) Oxidative \& nitrosative stress in depression: why so much stress? Neurosci Biobehav Rev 45:46-62.

106. Brinholi FF, Noto C, Maes M, Bonifácio KL, Brietzke E, Ota VK, Gadelha A, Cordeiro Q, Belangero SI, Bressan RA, Vargas HO, Higachi L, de Farias CC, Moreira EG, Barbosa DS (2015) Lowered paraoxonase 1 (PON1) activity is associated with increased cytokine levels in drug naïve first episode psychosis. Schizophr Res 166(1-3):225-230. 
107. Vargas HO, Nunes SO, Pizzo de Castro M, Bortolasci CC, Sabbatini Barbosa D, Kaminami Morimoto H, Venugopal K, Dodd S, Maes M, Berk M (2013) Oxidative stress and lowered total antioxidant status are associated with a history of suicide attempts. J Affect Disord 150:923-930.

108. Gałecki P, Talarowska M, Anderson G, Berk M, Maes M (2015) Mechanisms underlying neurocognitive dysfunctions in recurrent major depression. Med Sci Monit 21:1535-1547.

109. Dargél AA, Godin O, Kapczinski F, Kupfer DJ, Leboyer M (2015) C-reactive protein alterations in bipolar disorder: a meta-analysis. J Clin Psychiatry 76(2):142-50.

110. Maes M, Carvalho AF (2018) The Compensatory Immune-Regulatory Reflex System (CIRS) in Depression and Bipolar Disorder. Mol Neurobiol 55(12):8885-8903. 